\title{
Permanencias, transformaciones y desafíos en dos pesquerías artesanales de la Región Este de Uruguay
}

\author{
CONTINUITY, TRANSFORMATIONS AND CHALLENGES IN TWO SMALL SCALE \\ FISHERIES OF THE EAST REGION OF URUGUAY
}

\author{
D’Ambrosio, L.* Martínez, G.** González, V.** Keldjian, E.*** Clavijo, I.*** \\ Cuberos, V. ${ }^{* * * 1}$ \\ almejaypesacacesic@gmail.com \\ Recibido: 30/09/2019 Aceptado: 21/12/2019
}

\begin{abstract}
Resumen
En este artículo se describen los avances de la investigación sobre dos estudios de caso de pesquerías artesanales del Este del Uruguay. Mediante dicho estudio se busca contribuir al conocimiento de la interpretación, uso del espacio marítimo-costero y manejo de los recursos pesqueros de diferentes grupos dedicados a la pesca artesanal. Con foco en: la pesquerías de peces y bivalvos en Laguna Garzón y extracción de almeja amarilla en La Coronilla y Barra del Chuy. Luego de una exposición histórica de antecedentes sobre las localidades en cuestión que permiten comprender la configuración sociocultural actual, realizamos una breve caracterización sociocultural y biológica de ambas pesquerías. El abordaje metodológico utilizado es el antropológico y etnográfico. Asimismo, partiendo de una propuesta interdisciplinaria se articulan conocimientos de las ciencias biológicas entorno a las especies objetivo de las pesquerías y de los diferentes entornos medioambientales en los que se desarrollan estas prácticas.
\end{abstract}

Palabras clave: pesquería artesanal; cosmografías; territorialidades; manejo

\begin{abstract}
This article describes the advances in research on artisanal fisheries in the east of Uruguay. The aim of this study is to contribute to the knowledge of the interpretation and use of the maritime-coastal space and the management of the fishing resources of different groups dedicated to artisanal fisheries in the region. The focus is mainly on two case studies: the fishery of fish and bivalves in Laguna Garzón and the yellow clam fisheries in La Coronilla and Barra del Chuy. After having made a historical background presentation about the localities mentioned, we will see how the research proposes an anthropological approach to the practices and discourses generated by the different agents around the fisheries based on the fieldwork carried out with the interlocutors. At the same time, starting with an interdisciplinary proposal, the knowledge of the biological sciences is articulated around the captured species and the different environments in which these practices are developed.
\end{abstract}

Keywords: artisanal fisheries, cosmography, territorialities, management

\footnotetext{
1 *_Centro Universitario Regional Este - Universidad de la República.

**_Grupo de Estudios Pesqueros y de Impacto Ambiental Centro Universitario Regional del Este Universidad de la República ***_Centro de Investigaciones del Patrimonio Costero. Centro Universitario Regional del Este Universidad de la República.
} 


\section{Introducción}

El presente artículo presenta resultados del Proyecto: "Pesquerías artesanales en la costa Este de Uruguay: Aportes para su investigación y gestión”2, el cual tiene como objetivo el estudio de las pesquerías artesanales en la costa Este de Uruguay, buscando contribuir al conocimiento de la interpretación y el uso del espacio marítimo-costero y manejo de los recursos pesqueros que tienen los diversos grupos dedicados a las pesquerías artesanales. Para ello, nos propusimos realizar un estudio sociocultural e histórico en dos pesquerías artesanales de pequeña escala: una ubicada en la Laguna Garzón y la siguiente en la zona de playa entre las localidades de La Coronilla y Barra del Chuy. Es interesante detenerse en aquellas temáticas que surgen como transversales en los dos casos de estudio. Entre estas se destacan: los desafíos planteados para el manejo de las pesquerías, las transformaciones ocasionadas en el territorio tanto por propuestas de ordenamiento territorial y áreas protegidas, así como por modelos de desarrollo que parecieran modificar de una forma u otra el entorno, cambios ocurridos con las especies y las relaciones sociales intergeneracionales.

Una de las categorías centrales que atraviesa este artículo y el proyecto en general es el de "pesquería artesanal". Desde nuestro enfoque, englobamos en dicho concepto a "las diversas actividades vinculadas a la explotación y procesamiento de diversos bienes costeros, actividades desarrolladas, por hombres y mujeres, tanto en tierra como en el mar. Estas actividades están vinculadas directamente a la extracción de recursos marítimos para su consumo y comercialización. Es importante que en torno a ellas se desarrolla un conocimiento y apropiación del espacio marítimo-costero específico. En muchos casos se reconoce como espacio propio, es decir, que genera vínculos de arraigo y pertenencia al espacio de trabajo común donde se desarrolla buena parte de las tareas en tierra, las redes sociales y el grupo social que se forma en torno a la actividad" (D’Ambrosio, 2010:53); así como al espacio marítimo donde se desarrollan las actividades de extracción y navegación. Varios estudios (Migliaro y Santos, 2010; D'Ambrosio, Lembo, Amato y Thompson, 2010; Etchebehere y Geymonat, 2018) sobre la pesca artesanal en nuestro país, destacan la heterogeneidad de prácticas y formas de producción existentes al interior de la actividad, cuya:

2 Financiado por la CSIC en el marco de los llamados CSIC I+D (2017-2019). 
(...) dinámica particular está signada por la tensión entre la explotación de un recurso natural para la subsistencia y las lógicas de apropiación vinculadas al desarrollo del capital. Esta diversidad de intencionalidades en el desarrollo de la actividad productiva en relación con las particularidades locales hace que en la denominación de pesca artesanal convivan una cantidad de prácticas y situaciones heterogéneas" (Migliaro y Santos, 2010:3). Esto se explica en parte por la diversidad en el esfuerzo pesquero que presenta la pesca artesanal en Uruguay dentro de la categorización por ley (Tonelaje de Registro Bruto menor o igual 10) (Puig, Grunwaldt y González, 2010; Etchebehere y Geymonat, 2018). El estudio de estos modelos de producción, con implicancias diversas sobre los trabajadores, y sobre los recursos naturales, ha sido clave para comprender las formas de "trabajar el mar" y los sistemas de agua dulce.

En el presente análisis identificamos aspectos que hacen a la complejidad de la gestión de los bienes naturales así como al ordenamiento territorial, en particular trataremos aquellos que se vinculan de alguna forma a las pesquerías artesanales. En este sentido los casos de estudio reflejan dos procesos, por un lado el ingreso de un área al Sistema Nacional de Áreas Protegidas $^{3}$; Y por otro, vinculado a la nueva ley de pesca 19.175 en el 2013 y su decreto reglamentario (115/018), y al proceso que se inició en 2009 de implementación de un Enfoque Ecosistémico Pesquero que incluye el co-manejo consultivo como herramienta de gobernanza.

Consideramos que conocer e integrar las formas de propiedad de los diversos grupos involucrados con el espacio marítimo-costero, su cosmografía y el conocimiento local sobre el medio marino debe incluir el aspecto sensorial, gestual y cinético en los usos de artes (Florido, 2002, citado en García Allut, 2003). Lo anterior es imprescindible tanto para la implementación del Área Protegida y su plan de manejo, en el caso de Laguna Garzón así como también para la implementación del "Enfoque Ecosistémico Pesquero"4 (EEP). En muchos

\footnotetext{
3 "Las áreas protegidas o parques naturales existen en Uruguay desde mediados del siglo XX, pero su incorporación a un Sistema Nacional de Áreas Protegidas (SNAP) gestionado por el Estado central es una novedad de comienzos del siglo XXI. La Ley 17.234 promulgada en marzo de 2000, estableció la creación de un Sistema Nacional de áreas Protegidas. 111.523 hectáreas ingresaron al SNAP entre el 2005 y 2010, en un total de ocho áreas, tres de las cuales se encuentran en Rocha (Santos; 2011:61).

4 "Existe una tendencia global hacia la implementación del Manejo Ecosistémico de Pesquerías. Esta nueva estrategia analiza las pesquerías considerando las interdependencias ecológicas entre las especies que ocurren en el ecosistema y su relación con el ambiente, así como las
} 
países pescadores la gente ha desarrollado conocimientos nativos, locales o tradicionales (Morais Chiaravalloti, 2019) que han resultado fundamentales para la regulación del acceso a las zonas de pesca y/o a las áreas protegidas (Palsson, 1989 citado en D’Ambrosio, 2010; Basurto, 2005; Berkes, 2008; Saavedra-Díaz, Rosenberg y Martín-López, 2015; de la Rosa, 2016). En este sentido, Palsson, (1989) plantea que las políticas públicas deberían incorporar estas prácticas informales de manejo, para generar lo que él llama una forma de co-manejo" (D’Ambrosio, 2010:60). Los resultados que presentamos aquí dan cuenta de las modalidades de pesca y los conocimientos ecológicos generados en las prácticas de la localidad por los grupos pesqueros. Lo que Ingold y Kurttila, (2000) entienden como conocimiento tradicional generado en las prácticas de localidad por oposición al modelo que llaman genealógico. Dicho conocimiento y sus prácticas asociadas, orienta y sustenta el funcionamiento de sistemas de manejo comunitario. Siendo el mismo un conocimiento empírico y práctico, producto de un proceso acumulativo y dinámico de experiencias prácticas y de adaptación al cambio. Es local, holístico y portador de una cosmovisión que integra aspectos físicos y espirituales.

La metodología empleada en esta investigación fue una combinación de métodos, desarrollando un trabajo etnográfico de observación participante, entrevistas etnográficas y entrevistas semi-estructuradas, asimismo se incorporó la búsqueda de datos etnográficos en fuentes históricas. Sobre este último aspecto, los reservorios consultados fueron el Archivo de Maldonado (Centro de bienes culturales - Casa de la Cultura), Archivo de Rocha (Centro Cultural María Élida Marquizo), Biblioteca Nacional, Archivo del PAS-CIPAC, Biblioteca de la Facultad de Humanidades, Archivo de la Prefectura Nacional Naval, y diversos sitios web como DINAMA, Vida Silvestre, Karumbé, Intendencia de Rocha, Museo Nacional de Historia Natural, Ministerio de Vivienda Ordenamiento Territorial y Medio Ambiente, PROBIDES, entre otros.

Este artículo se divide en cinco partes. En una primer parte presentamos algunos de los avances generados a partir de la revisión sistemática de fuentes históricas secundarias para La Coronilla y Barra del Chuy, donde se desarrolla actualmente la pesquería de la almeja amarilla. En la segunda parte realizamos una breve caracterización de las pesquerías de la almeja. En la tercer parte presentamos los avances generados en la revisión de fuentes 
históricas para el caso de Laguna Garzón, para luego desarrollar los avances del análisis realizado, poniendo el mismo énfasis que para el caso de la pesquería de la almeja, a partir del trabajo etnográfico llevado a cabo en torno a las pesquerías artesanales y al área de estudio. En la quinta parte, presentaremos las consideraciones finales para ambos casos, que se desprenden del proceso de investigación realizado al momento.

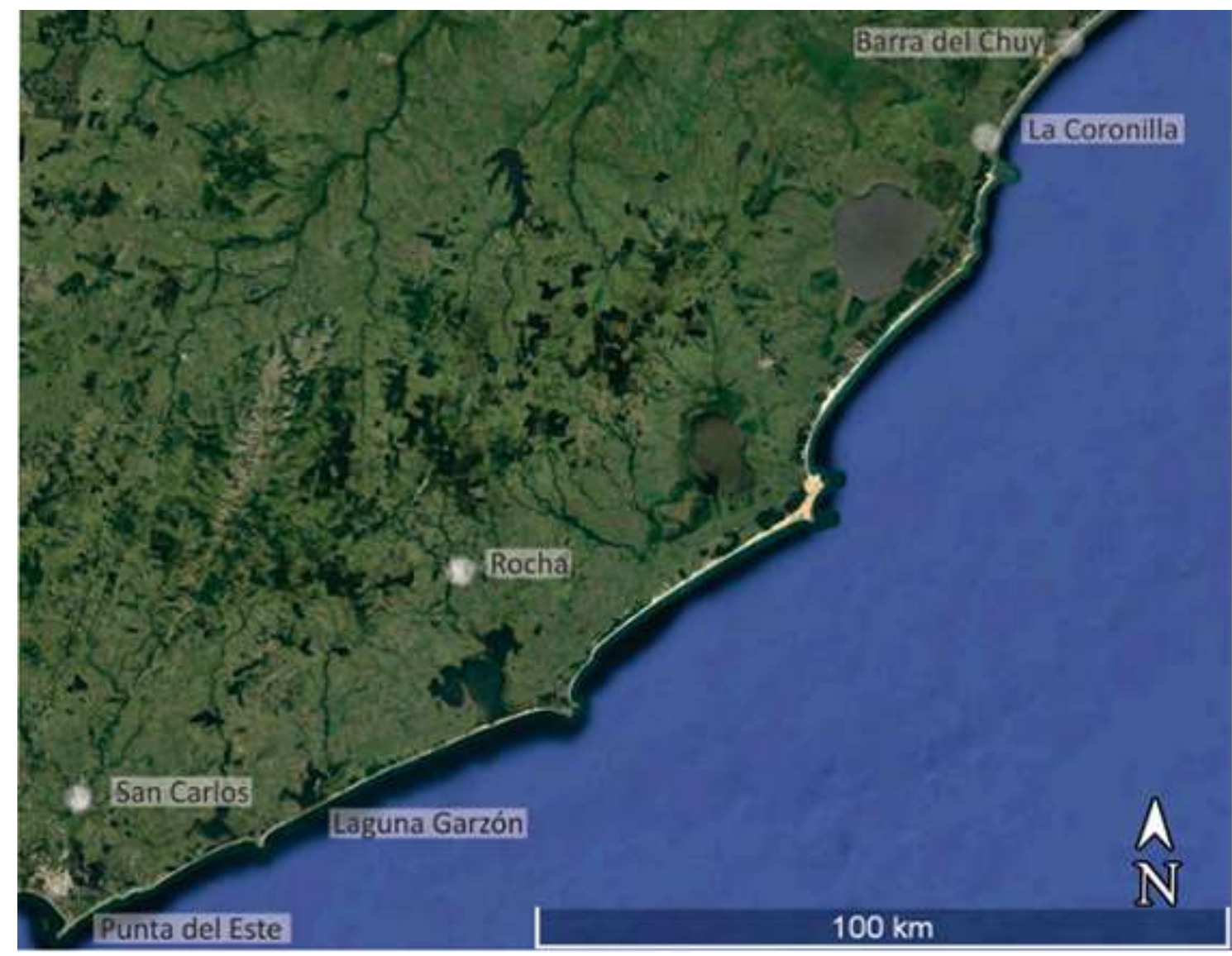

Figura 1- Localización de los sitios de estudio. Fuente: Google Earth.

\section{Antecedentes históricos}

\section{Proceso de construcción del balneario La Coronilla y Barra del Chuy}

Para comprender la configuración sociocultural y productiva actual en la que está inserta la pesquería de la almeja, consideramos oportuno retrotraernos al proceso histórico de formación de los dos poblados: La Coronilla y Barra del Chuy. Pues muchas de las características y dinámicas de la pesquería están vinculadas a dicho proceso, por ejemplo el 
desarrollo del turismo en la región, aspecto que comparten las dos pesquerías abordadas en este artículo.

Asimismo ambos casos presentan matices de lo que se ha llamado "zona de sacrificio", en el caso de la pesquería de la almeja por la construcción del Canal Andreoni, como veremos en este apartado, mientras que en el caso de Laguna Garzón por la construcción de un puente sobre la laguna sin previo estudio de impacto ambiental. Según Santos, (2017) "los movimientos ambientalistas han acuñado el concepto de 'zona de sacrificio' para hacer referencia aquellos lugares que concentran industrias contaminantes en contextos de comunidades o poblaciones débiles o víctimas de la vulneración de sus derechos" (Santos, 2017:15). En tal sentido, ambas políticas estatales, la aprobación de un sitio RAMSAR como Bañados del Este y Franja Costera (Sitio 290) y al mismo tiempo la de creación de canales para desecación de campos, pese a no ser contemporáneas en este caso, permiten ver desde una perspectiva integral las políticas medioambientales adoptadas a nivel nacional en una aparente contradicción.

El territorio donde se ubica el actual balneario La Coronilla aparece registrado por primera vez en las descripciones geográficas hechas por los navegantes (derroteros); se denominaba a este tramo de la costa: "costa de castillos" (Lobo y Riudavets, 1868). Este nombre se origina en la particular forma de los islotes (Castillos Chico y Grande) que constituyen, junto a las puntas rocosas y las ensenadas que a sus lados se forman. El nombre La Coronilla se debe a que la punta de castillo chico "está cubierto de arbustos de igual denominación” (Lobo y Riudavets, 1868: 55).

Es precisamente por esta mirada marítima del territorio que la zona de La Coronilla desde mediados del siglo XIX era vista como un puerto natural de ventajosas condiciones, según lo describe el ingeniero José María Reyes (1859).

Desde la perspectiva de tierra, La Coronilla tiene sus más remotos antecedentes históricos en la fundación en 1885 de la colonia agrícola Santa Teresa que luego paso a denominarse pueblo Gervasio. El centro urbano o pueblo de la colonia Santa Teresa llevaría el nombre de pueblo Gervasio. Sin embargo, este emprendimiento fue de poca duración y los colonos abandonaron el lugar; en la zona, años después, se hicieron las obras de desecación de tierras sumergidas impulsadas por el ingeniero Luigi Andreoni, quien construyó canales 
mediante los cuales logró el drenaje de las aguas en dirección al Atlántico. Esos trabajos concluyeron en 1910, cuando se abrió el último canal de los bañados en Santa Teresa.

El desarrollo turístico tiene una relevancia importante para la región, y La Coronilla no ha sido la excepción. Para la década de 1930 se retomó el proyecto de urbanización en la zona de los antiguos terrenos de Gervasio. En 1935 se inauguró el primer hotel, Las Maravillas en 1941 abrió el Parador La Coronilla (actualmente Parque Oceánico). Para 1945, quedaba inaugurada la ruta 9 desde Rocha al Chuy, permitiendo el desarrollo turístico de la zona Este del departamento. En 1951 se lo declaró balneario turístico y se le denominó “La Coronilla” y se posicionó como un lugar de referencia para la temporada de verano.

En el año 1980 se amplió la cuenca del Canal Andreoni disminuyendo la calidad del agua en las playas de la zona y ocasionando que el esplendor del balneario decayera. A partir de ese momento la construcción se detuvo, los hoteles cerraron y luego volvieron a reabrir, pero con menos servicios y comodidades.

Los pescadores artesanales también vieron cómo desaparecían de la zona los cangrejos sirí y los lenguados, y disminuía drásticamente la pesca de lisas, borriquetes, corvinas y sardinas, así como la recolección de almejas, que desaparecieron de la playa (Sosa, 2007). Investigaciones realizadas en Facultad de Ciencias comprobaron el impacto de este canal sobre invertebrados que viven en playas arenosas determinado por la disminución de la salinidad (Lozoya y Defeo, 2006; Lercari y Defeo, 2006, Romero, Lercari, Ortega y Defeo, 2019) y por el impacto no letal de los herbicidas (Sauco, Eguren, Heinzen y Defeo, 2010).

\section{Antecedentes Barra del Chuy}

La barra del Chuy, junto a la localidad del Chuy tiene su origen en su situación geográfica de ser el arroyo Chuy línea divisoria entre Uruguay y Brasil. Los antecedentes históricos más antiguos de esta región están registrados en el Diccionario Geográfico del Uruguay de Orestes Araujo (1903), donde plantea su importancia histórica debido a que: "El fundador del fuerte San Miguel, el Brigadier Silva Páez, hizo alto en las costas de dicho arroyo para levantar también el térreo fortín de Jesús, María y José, que con el anterior constituían los más fieles testigos del avance lusitano en dominios españoles. Llega la demarcación de 1784 
(tratado San Ildefonso, 1777), y la Barra del Chuy sirve de punto de arranque, plantándose allí el primer mojón de España a los 33 15'13"S. Y 47 12`30”O., " (Araujo, 1903: 236).

La zona comenzó a ser poblada de forma estable como parada obligada de viajeros a Santana Do Livramento en Brasil e incluso a quienes viajaban a Rio Grande do Sul. Allí surgió una intensa actividad comercial en torno a las diligencias y su situación de frontera (está es otra de las características que tiene una fuerte impronta hasta el día de hoy y que ha incidido en múltiples dimensiones de la pesquería). Para la zona costera la Revista Histórica Rochense da origen al surgimiento del balneario en el año 1909 cuando los hermanos de apellido Acosta compran los terrenos. En los años 30 Samuel Priliac comienza a fraccionar las tierras y durante las décadas de 1940 y 1950 es cuando se da el mayor auge de ventas de terrenos en la zona. Es a partir de 1990 que debido a las mejoras en el transporte que conecta a la Barra del Chuy con el Chuy comienza a vivir más gente durante todo el año. (Dornel; s/f).

\section{La pesquería artesanal de la almeja amarilla}

La especie objetivo de la pesquería es la almeja amarilla Amarrilladesma mactroides (Reeve, 1854) la cual es uno de los recursos característicos de la zona. La almeja amarilla es un molusco bivalvo filtrador que incluye la mayoría de las almejas marinas "típicas". Su talla máxima alcanza $80 \mathrm{~mm}$. Se distribuye desde Cabo Frío, Brasil (23 $\mathrm{S}$ ) hasta el sur de la provincia de Buenos Aires, Argentina $\left(41^{\circ} \mathrm{S}\right)$ en playas arenosas de poca pendiente y arena fina. En el cinturón de playa de 22 km entre las localidades de La Coronilla y Barra del Chuy constituye el único sitio del país donde actualmente se desarrolla esta pesquería.

Su explotación se lleva a cabo desde el año 1950; la modalidad de extracción y las artes de pesca utilizadas se mantienen igual desde sus inicios. Esta se caracteriza por la extracción del bivalvo de la faja costera arenosa por medio de palas y de forma manual. A lo largo de estas décadas, las mismas familias han perdurado en su práctica, por lo que han desarrollado un conocimiento etno-ecológico significativo en torno a la especie y a su extracción, el cual trasmiten a las nuevas generaciones (D’Ambrosio et al., 2010). Al respecto, a diferencia de lo que ocurre con otras pesquerías artesanales observamos que las nuevas generaciones continúan con la actividad. 
Figura 2- Carro de caballo utilizado para trasladar las almejas extraídas de la costa. La Coronilla, 6 de noviembre de 2018.

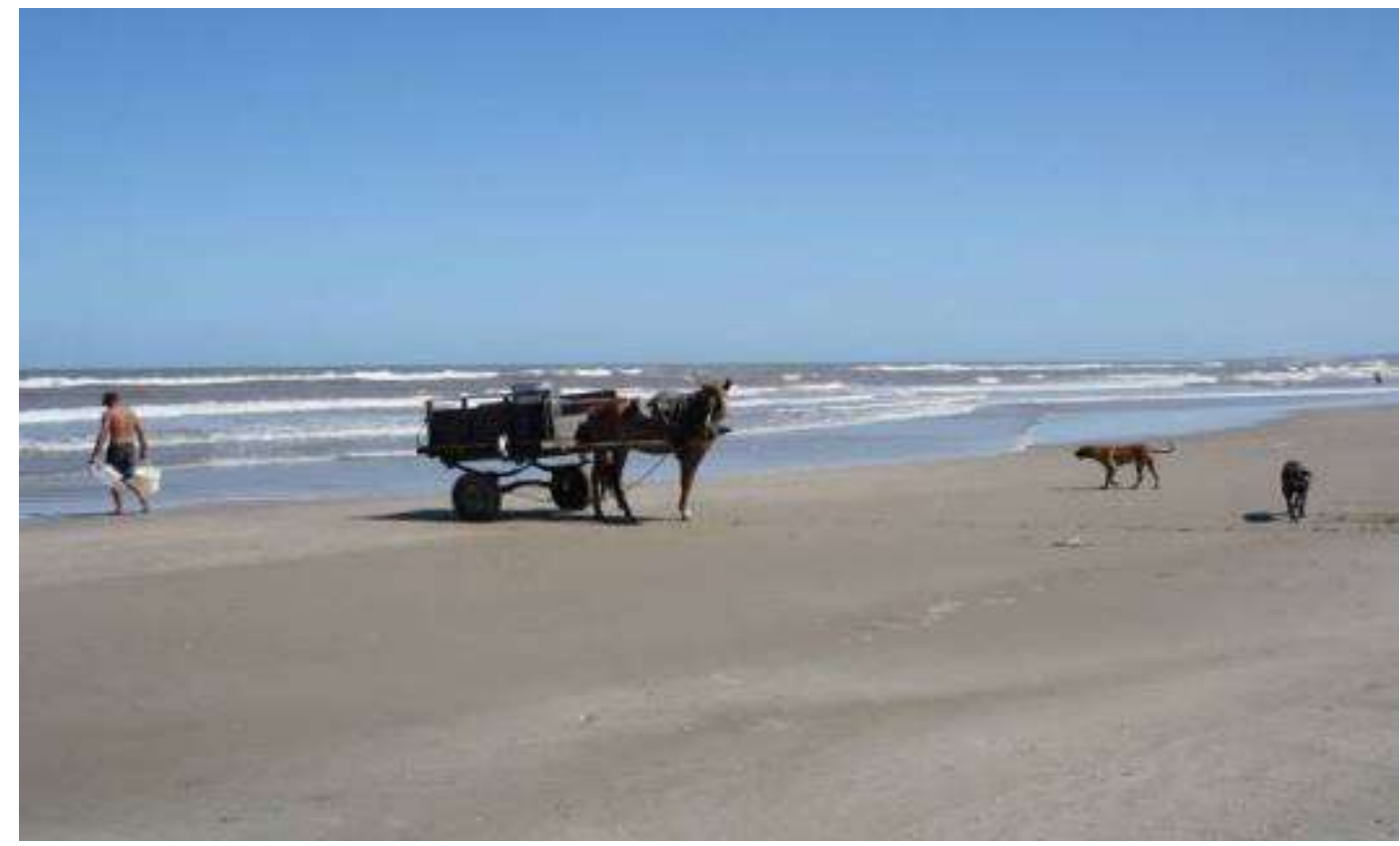

\section{Ser almejero}

Los pescadores de almeja de estas localidades presentan cierta identificación con el recurso pesquero así como también con la playa. Se observan elementos que hablan de una legitimidad como almejero. Entre estos se destacan: la antigüedad, "el estar en la playa" hace mucho tiempo. Asimismo se destaca el ser residente permanente de La Coronilla o Barra del Chuy, las personas que vienen solamente para la zafra no son legitimadas de la misma forma como almejeros, por ejemplo María que viene de Montevideo, observa:

Et: “Claro y ahí te iba a hacer una pregunta ¿cuándo vuelve la almeja por qué ustedes dicen bueno si volvemos y queremos sacar?"

M: "Porque el tema es que siempre esto fue la raíz de nosotros digo nosotros nos criamos en la playa digo y el pueblo no era lo nuestro, estábamos ahí por más bien por obligación este... entonces cuando nosotros empezábamos a venir los veranos que veníamos a pasear, y bueno ta' lo nuestro, está la almeja, nos criamos con esto y fue cuando empezamos de vuelta a volver a..."

Por otro lado vinculado con esta identificación se observa la llegada de muchas de las familias de almejeros actuales hacia la década del 60. Dicho proceso estuvo vinculado a la 
construcción del Canal Andreoni, la Salinera, el desarrollo de sociedades pecuarias y del cultivo del arroz, y al desarrollo del balneario así como también de las fábricas de conservas en Palmares de La Coronilla y las ubicadas sobre el $\mathrm{A}^{\circ}$ Chuy.

\section{Las distintas fases de las modalidades de gestión de la pesquería.}

Durante todas estas décadas la explotación de la especie ha atravesado variaciones significativas, pasando por etapas de gran explotación sin regulación, extinciones masivas, regulación estatal y co-manejo.

La pesquería funcionó bajo régimen de acceso abierto hasta 1986 donde los altos niveles de esfuerzo pesquero determinaron que las capturas como la abundancia se redujeran drásticamente (Defeo, 1989, 1996). El período 1987-1993 se caracterizó por el desarrollo de una experiencia de co-manejo no institucionalizado en el cual se establecieron medidas de manejo consensuadas entre la comunidad pesquera y la Dirección Nacional de Recursos Acuáticos (DINARA actualmente, INAPE en ese momento) para regular la explotación de este recurso incluyendo un cierre temporal de la pesquería (Defeo, 1989). La misma se reabrió pero en 1994 ocurrió un proceso de mortandades masivas que determinó la suspensión de la pesquería hasta 2008 (Ortega, Castilla, Espino, Yamashiro y Defeo, 2012). Es interesante mencionar que hasta el momento no se encuentra una explicación sobre las causas de las mortandades, existiendo varias conjeturas tanto de científicos como de los propios almejeros.

Entre 1994 y 2007 se registraron en Uruguay principalmente ejemplares caracterizados como reclutas y juveniles, y adultos pero en muy bajas densidades (Defeo, et al., 2018). Finalmente se estableció la veda total del recurso y como consecuencia el grupo de pescadores migró a otros sectores de la economía como el comercio, actividades vinculadas al campo, y la construcción, entre otros (de la Rosa, 2016).

A partir de la recuperación parcial del stock pesquero en 2007, en 2009 comenzó nuevamente su explotación bajo un proceso de co-manejo, concentrándose durante la época estival cuando coincide con la mayor demanda del mercado gastronómico local (Gianelli, Martínez y Defeo, 2015). En este sentido, al igual que veremos para el caso de la pesquería en laguna Garzón, se presenta una marcada estacionalidad por la actividad turística En el marco del proceso de co-manejo se conformó un grupo de almejeros, integrado por 39 permisarios, 
que permitió iniciar un proceso de recuperación del stock pesquero qque continúa actualmente) sostenido por el acuerdo entre pescadores y DINARA, a efectos de generar y respetar las medidas de ordenamiento. Dicho proceso se fortaleció ante el establecimiento de mecanismos de gobernanza. Entre 2009-2012 se estableció un régimen de asamblea entre pescadores e instituciones públicas, y a partir de 2012 se conformó un Consejo de Pesca vinculado a este recurso que continúa operando actualmente, y cuyo carácter se definió como consultivo a partir de la nueva Ley de Pesca.

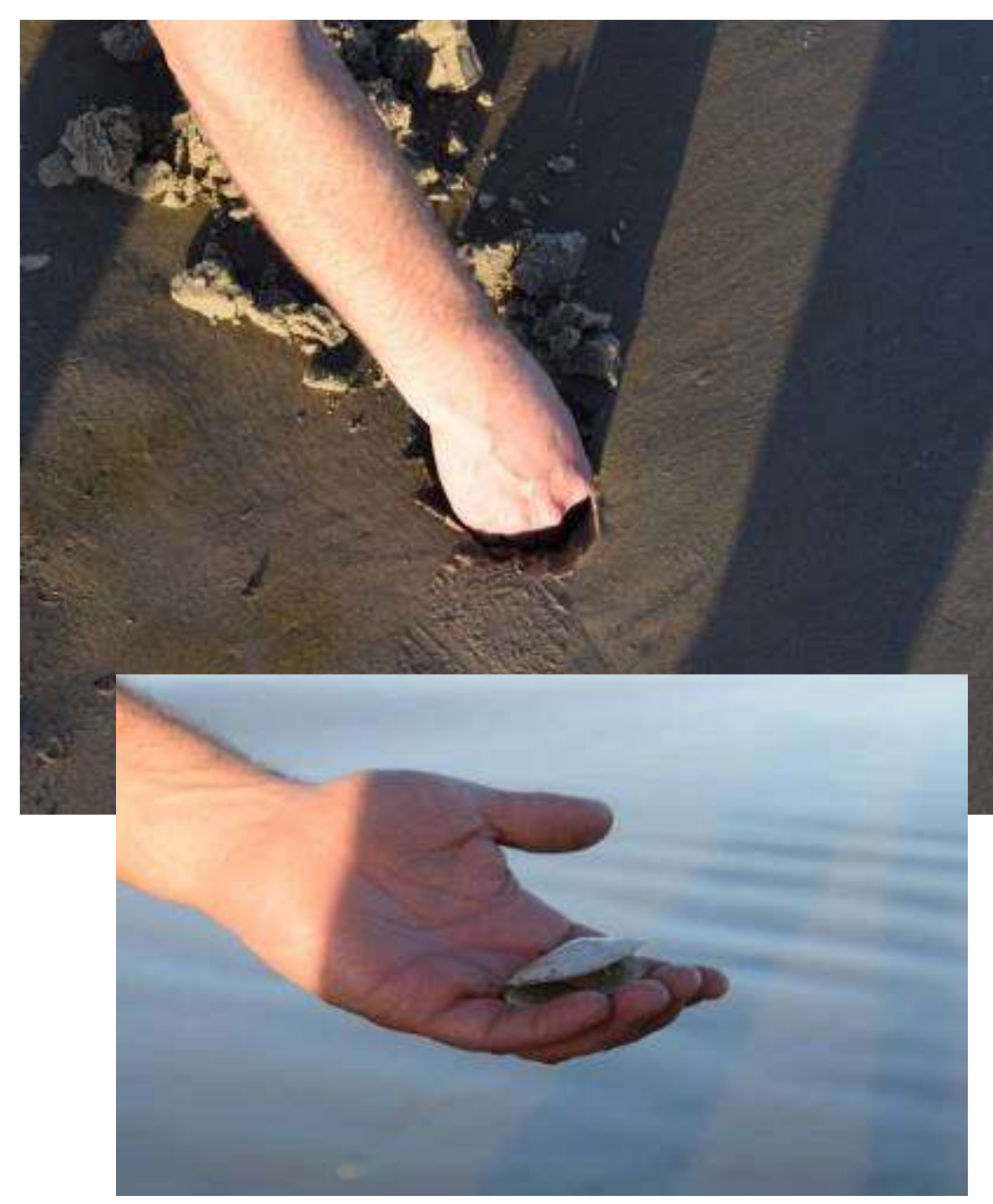

Figura $\quad 3-$

Búsqueda de almejas con la mano. La Coronilla, 6 de noviembre de 2018.

Desde el inicio de la pesquería la comercialización de almeja ha sido para carnada y para consumo en el mercado gastronómico. Las formas de venta históricas para consumo humano han sido: "purgada" entera, o en pulpa congelada sin arena y enlatadas. La venta al mercado gastronómico aumentó al 90\% del total de almeja extraída en un período de 4 años desde 2009 y los precios por kilo de almeja "sucia" en la playa aumentaron de ca. U\$S 1.90 en 2009 (Gianelli et al., 2015) a U\$S 4.72 en 2019 (com. Per. Almejas Palmares). 
A pesar de las mejoras observadas en el manejo de la pesquería y en la cadena de valor a través de los años, el incremento en frecuencia y duración de eventos de marea roja, los cuales determinan una clausura pesquera inmediata, representan un factor crítico que amenaza la sustentabilidad económica de la actividad tanto para los pescadores como para la planta de procesamiento (Defeo, 2015; Gianelli et al., 2015; Defeo et al., 2018). Estos eventos, sumados al efecto sostenido de la variabilidad climática (i.e. Intensificación de vientos fuertes, aumento del nivel del mar) impactan en el desarrollo de la actividad pesquera afectando directamente a la comunidad de almejeros, haciendo de ésta una pesquería por demás vulnerable (Defeo et al., 2013; 2018).

Pese a todas las vicisitudes, en la actualidad las almejas se comercializan vivas y se purgan de arena en piletas de la única planta habilitada por DINARA en el país. Dicha planta es propiedad de dos permisarios que a partir de búsquedas estratégicas para aumentar el valor agregado del recurso y así incrementar el precio de venta en la playa, en 2012 se forma la empresa Almejas Palmares dirigida por 2 permisarios. Como consecuencia se comienza a vender almeja purgada al mercado gastronómico de Rocha, Maldonado y Montevideo, siendo ésta, la única planta artesanal de recursos pesqueros habilitada en Uruguay. 


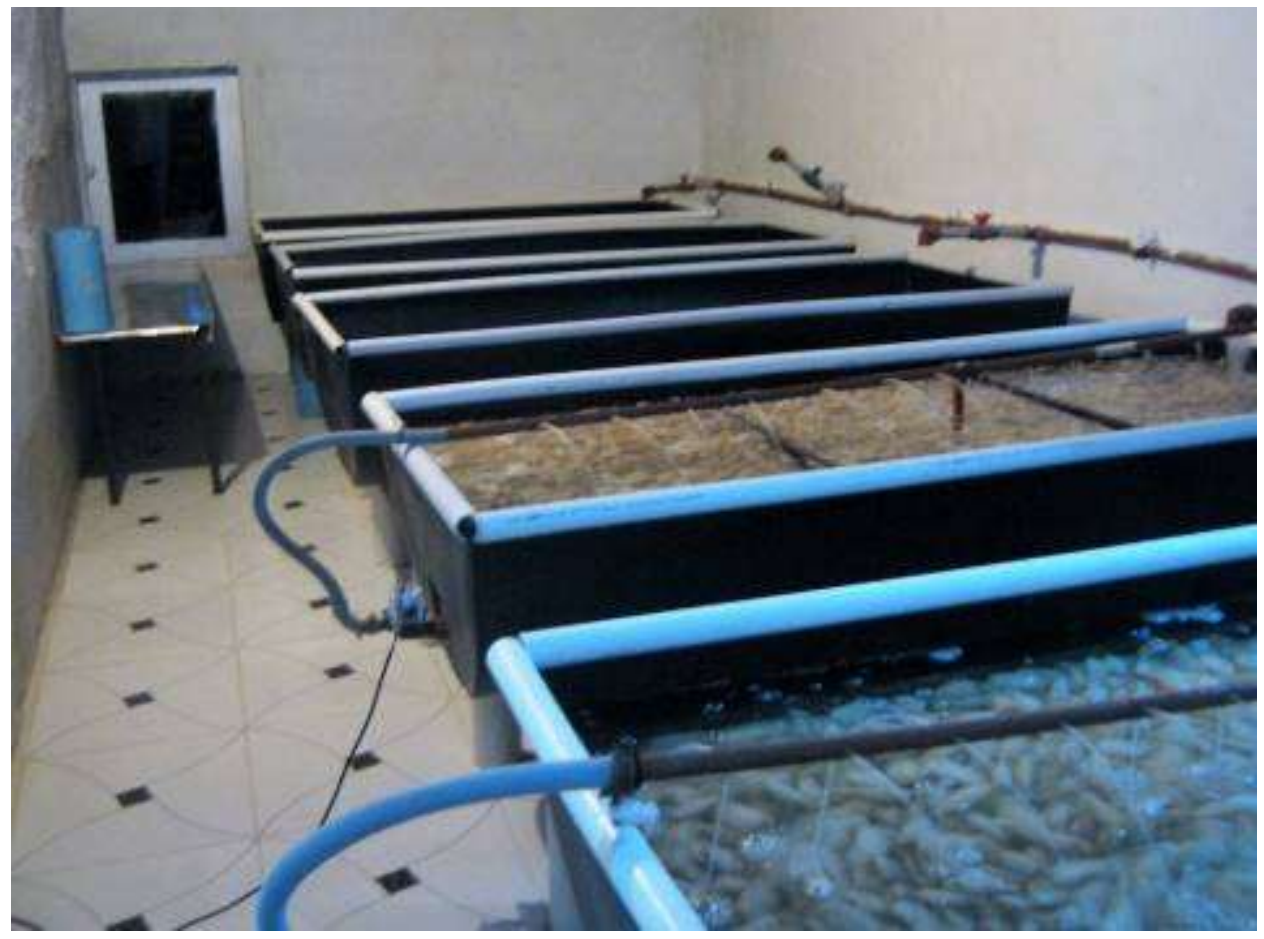

Figura 5- Planta de purgado. La Coronilla, 4 de setiembre de 2017.

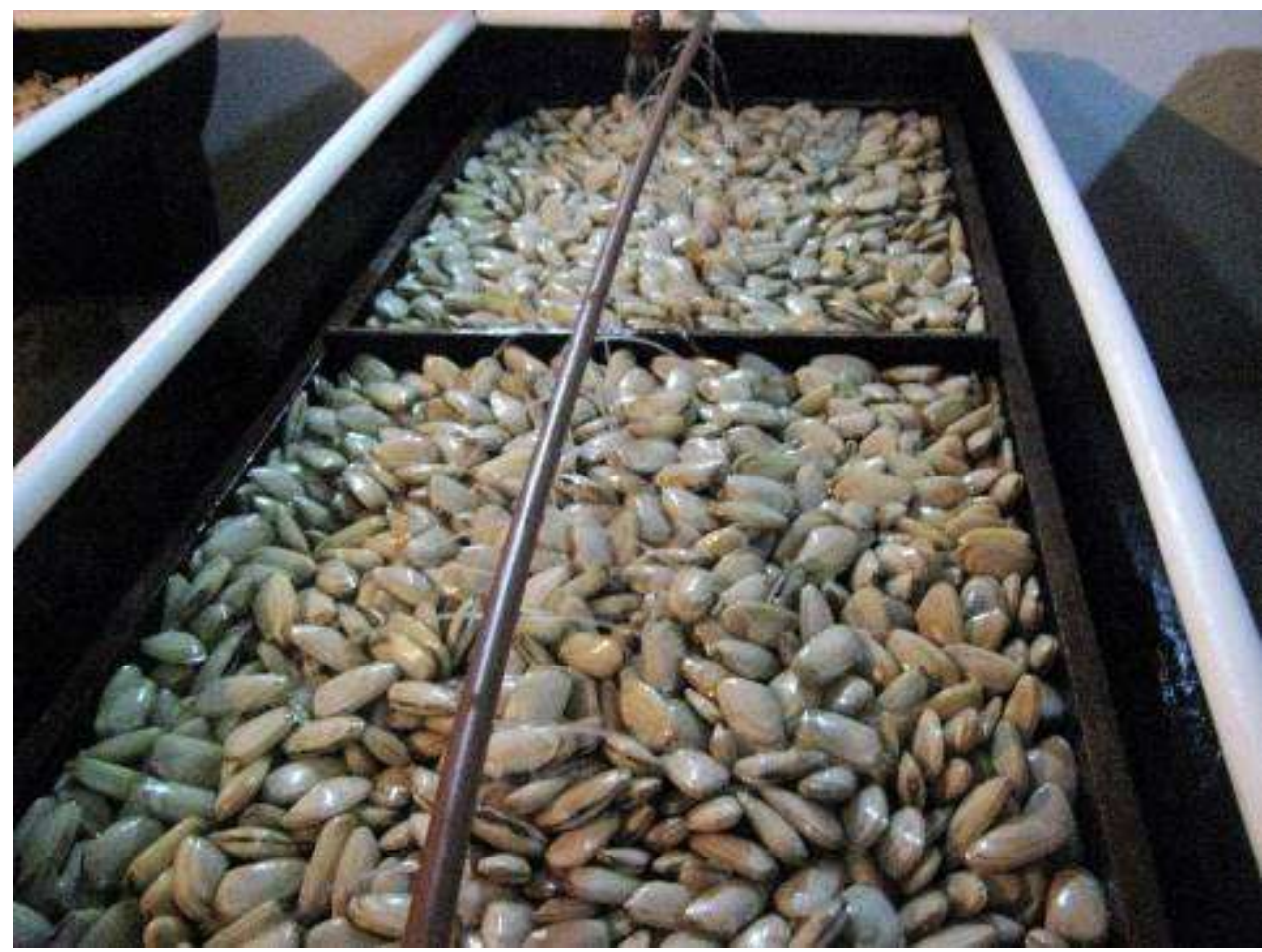

Figura 6- Piletas donde se realiza el de purgado de la almeja amarilla. La Coronilla, 4 de setiembre de 2017. 
El proceso de purgado consiste en la eliminación de la arena contenida dentro de la almeja; el mismo dura por los menos 48 horas. Las almejas se depositan sobre una rejilla o zaranda dentro de 5 piletas de 500 litros con agua de mar de la zona. La misma se extrae del mar con bombeo de forma manual, almacenada en un tanque y luego trasladada a la planta en vehículo. El agua de las piletas debe ser renovada entre 2 y 4 veces por día para evitar la muerte de almejas. Esto podría deberse a la intensificación del filtrado (alimentación) generando un eficiente purgado en 48 horas.

Recientemente se terminó de construir la planta de congelado con el objetivo de mantener la oferta constante de almeja para los restaurantes durante todo el año conservando la alta calidad del producto. La trazabilidad del recurso y la valoración de los cocineros profesionales sobre su calidad, el cual llega vivo al restorán, han hecho que esta empresa permanezca en funcionamiento a pesar de que las almejas amarillas tienen el doble de costo que las almejas del mismo género importadas desde Chile. Desde el 2015, la almeja amarilla forma parte del Arca del Gusto de Uruguay, de la organización internacional Slowfood.

Observamos que está transformación y desafío en la modalidad de comercialización ha permitido el interés de las nuevas generaciones para continuar con una actividad familiar, que es zafral y que implica, como mencionábamos anteriormente, el tener que lidiar con riesgos vinculados a la especie y al entorno en el que crece. Asimismo, en esta pesquería se observa la complementariedad entre la actividad pesquera y la turística pues muchos de los consumidores de los bivalvos son turistas tanto de Rocha como de Maldonado. Otro de los desafíos que enfrenta la pesquería son los muestreos para determinar la apertura o no de la pesquería.

\section{Muestreos participativos: articulación de conocimiento científico y ecológico de la práctica de la localidad.}

Los muestreos del recurso han sido el elemento clave de la gestión y ha estado presente en algunas etapas del proceso del co-manejo, por iniciativa personal de uno de los gestores-investigadores. A partir de estas instancias se investiga la biomasa del recurso y se determina la biomasa comercial disponible. Los resultados arrojados en esta instancia de 
investigación biológica constituyen la principal fuente de datos para determinar la apertura de la pesquería.

Ambos conocimientos se articulan en los muestreos. Estos han sido la forma de calcular la disponibilidad y abundancia del recurso. La cantidad que se registrará en determinada época era fundamental para establecer el levantamiento de la veda y comenzar la extracción en cada temporada.

En estos muestreos fue frecuente (durante un período de tiempo determinado) que se utilizara la metodología de "muestreo participativo". Este tipo de metodología articula ambos saberes, el científico y el de la práctica de la localidad. La aplicación de este tipo de muestreo produce a su vez diversos efectos. Por un lado, tiene la capacidad de generar un resultado positivo empleando técnicas efectivas para la localización de las almejas, por utilizar los conocimientos de los arrancadores que se dedican a encontrarlas todos los años y conocen las particularidades de las playas. Y por otro lado, genera un resultado legitimado- desde el conocimiento científico- del conocimiento de los pescadores, ya que su conocimiento es puesto en práctica para tomar decisiones de gestión y manejo.

Uno de los elementos fundamentales para la efectividad del muestreo es la profundidad en la que se buscan las almejas en la arena. Según los almejeros es necesario escarbar al menos hasta un metro de profundidad desde la superficie para encontrarlas.

Según los relatos de algunos almejeros hubo una ocasión en que se realizó un muestreo sin los almejeros. La metodología aplicada pareciera no haber contemplado el tema de la profundidad sugerida por los arrancadores, sino que habrían llegado hasta los $30 \mathrm{~cm}$. de profundidad. Esto generó un resultado de cálculo de la biomasa inferior al esperado para dicha época del año. Al parecer en este resultado se basaron los agentes estatales encargados de habilitar la extracción y habría retrasado el comienzo de la temporada perjudicando a los almejeros.

Vemos como claramente existe un vínculo sumamente cercano y de afinidad entre algunos de los gestores principales del Estado y algunos pescadores. Este sin dudas es alimentado seguramente por un interés común: la preservación de las almejas. En tal sentido, la circulación de saberes se da de una manera recíproca. Los pescadores por ejemplo transfieren sus saberes sobre las variantes climáticas y ecológicas generadas a partir de la 
observación cotidiana de la playa y el contacto directo con el medioambiente. Por contrapartida, los biólogos aportan información en relación a las características biológicas de la especie, sus propiedades morfológicas, sus ciclos naturales y de reproducción.

Ambas formas de conocimientos, alimentan el saber y la práctica de los otros. Sin embargo, esta relación de colaboración encuentra tonos de conflicto cuando nos enfocamos en los lazos y relaciones sociales en juego. Por ejemplo, el hecho de pertenecer al campo de la burocracia estatal y tener el poder de regulación sobre los recursos pesqueros, de los cuales los almejeros dependen para subsistir.

Al mismo tiempo, la confianza depositada en los pescadores por parte de algunos de los investigadores-gestores es un factor significativo para comprender estas relaciones. Ya que, la confianza que proviene del reconocimiento a una larga trayectoria en el oficio, genera el efecto de legitimidad buscado por los pescadores para recibir su permiso de pesca, y lo que va aún más allá, otorgárselo a otros. Este proceso tiene un doble efecto, por un lado promueve en los pescadores un sentido de pertenencia con la pesquería. Por otro lado, genera un efecto de responsabilidad frente al recurso, siendo también los mismos pescadores los actores sociales designados consuetudinariamente para supervisar la explotación irregular. Esta responsabilidad no es vista con muy buenos ojos por algunos de los pescadores, pues expresan que no sienten garantías para poder ejercer el control sobre la extracción ilegítima dada la escasa presencia estatal y dado que este rol no es acompañado de la posibilidad de decidir sobre las condiciones de explotación del recurso, esta responsabilidad se vive muchas veces como "más trabajo". Siendo esta perspectiva nativa, otro de los desafíos que debiera tomar la propuesta de co-manejo. Quizás ajustando las responsabilidades de los pescadores a su capacidad de tomar decisiones. Principalmente sobre la gestión estatal de la pesquería, por ejemplo en el establecimiento de los períodos de vedas y cupos, entre otros aspectos.

\section{Antecedentes históricos}

\section{Las pesquerías artesanales en Laguna Garzón y José Ignacio}

Para comprender la configuración sociocultural y productiva actual en la que está inserta la pesquería artesanal en Laguna Garzón, consideramos oportuno retrotraernos al proceso histórico de la región y a las primeras referencias. Pues, al igual que para el caso de la 
pesquería de la almeja, muchas de las características y dinámicas de la pesquería artesanal en Laguna Garzón están vinculadas a dicho proceso.

Las primeras referencias que encontramos de la Laguna Garzón y José Ignacio corresponden a fines del siglo XVIII en los trabajos de descripción geográfica encomendados por la Real corona española a Andrés de Oyarvide (1790); su obra es minuciosa en detalles descriptivos de la costa y para esta zona menciona la existencia de ranchos de pescadores.

Las siguientes referencias corresponden a la segunda mitad del siglo XIX, en el derrotero de navegación del Río de la Plata de Lobo y Riudavents (1868); se refieren a la zona como la "Punta de José Ignacio" y mencionan características de la Laguna Garzón. Finalmente, a comienzos del siglo XX en el Diccionario Geográfico del Uruguay de Orestes Araujo (1903) se encuentran descripciones geográficas en detalle de la barra y la Laguna de Garzón, así como también del arroyo, la laguna y punta de José Ignacio.

Otros episodios aislados que se relacionan a esa zona de estudio corresponde a los siniestros marítimos que allí sucedieron. En los registros de estos episodios se encuentran testimonios sobre la ayuda proporcionada por los lugareños a los náufragos o a la posterior reutilización de los materiales que se podían rescatar.

A mediados del siglo XX el siguiente hito que sucede en la zona es el fraccionamiento del balneario El Caracol (1945-1948) y las primeras intenciones de construir un puente para la continuidad de la ruta 10 que cruzara la barra de la Laguna Garzón. Además, en el año 1976 la laguna Garzón fue declarada Parque Nacional Lacustre y Área de Uso Múltiple.

A partir de la década del noventa se comienzan a realizar diversos estudios que contemplan y analizan a las comunidades de pescadores de la zona (Vitancurt y Fagetti, 1995; de Álava y Rodríguez, 2007). Los mismos dan cuenta de los modos de comercialización a través de los "levantadores" que llegaban desde la Paloma y Maldonado. El precio del pescado era fijado por estos "levantadores" y variaba según las estaciones. Ya en estos estudios se destacaba la marcada estacionalidad por la actividad turística en la zona que llevaba a un aumento en el precio al venderlo directamente al turista (Vitancurt y Fagetti,1995). 
Durante el periodo de abril de 1994 hasta la construcción del actual puente (polémico e innovador en su creación ${ }^{5}$ ) el transporte en balsas del MTOP fue emblemático y era un atractivo más para los visitantes. Funcionaban, en forma gratuita, dos balsas en verano y una en invierno. Éstas transportaban hasta tres vehículos cada una con un sistema muy simple: la balsa es amarrada a una lancha y ambas navegan acoderadas, impulsadas por la energía del pequeño motor de la lancha. El cruce insumía dos minutos y medio y por año cruzaban más de 20.000 vehículos (Sosa, 2006).

\section{Las pesquerías artesanales de Laguna Garzón}

La Laguna Garzón se encuentra en el límite de los departamentos de Rocha y Maldonado, desde el punto de vista pesquero pertenece a la zona K que corresponden a las lagunas costeras. Constituye una laguna de agua salobre, cuyo cuerpo de agua ocupa 1.500 hectáreas y su cuenca 69.475 hectáreas. El grupo de pescadores de Laguna Garzón se encuentra asentado en la costa de la laguna, en el territorio del departamento de Rocha, al lado Este del puente circular ${ }^{6}$ que conecta con el territorio de Maldonado, aunque existe una familia que reside del lado fernandino. Las edificaciones de esta zona de la costa comprenden una cantidad no superior a veinte casas, hechas algunas de hormigón y bloques, otras con maderas y algunos pequeños galpones que ofician de depósito para la actividad pesquera. Estos últimos un poco más frágiles que las viviendas hechas con placas de compensados de madera, situadas en el espacio entre la laguna y la ruta, recientemente asfaltada, que la acompaña por algunos metros (Figura 7).

$5 \quad$ La autorización y posterior construcción del puente estuvo vinculada, como mencionamos anteriormente, al ingreso como SNAP. A partir de las gestiones de la Asociación Civil "Vida Silvestre" en el 2007 se propuso el ingreso de la laguna al SNAP. El 8 de enero de 2013 de acuerdo a la Resolución Ministerial 07/2013 el Ministerio de Vivienda, Ordenamiento Territorial y Medio Ambiente (MVOTMA) autorizó la construcción de un puente circular sobre la laguna. 


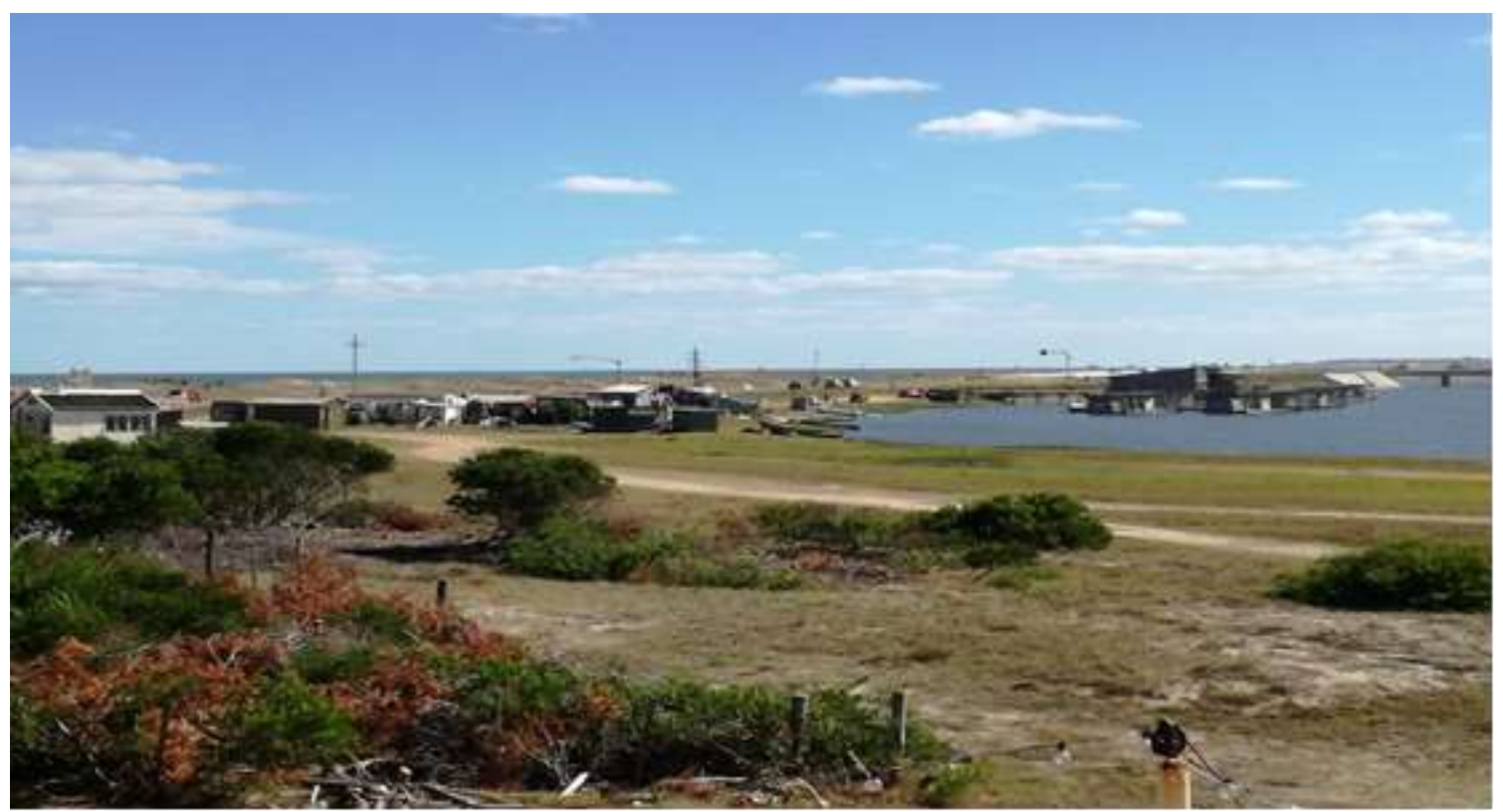

Figura 7- Casas de pescadores y Hotel Flotante en Laguna Garzón, 3 de febrero de 2018.

En dichas casas podrían vivir alrededor de cincuenta personas, aunque la mayoría no residen allí de forma permanente. Existen servicios de provisiones móviles que visitan el lugar con asiduidad semanal y que brindan muchos de los bienes de consumo deseados, por lo que para los más sedentarios no es necesario movilizarse con demasiada frecuenta. Los ómnibus que conectan Laguna Garzón con Montevideo finalizan su recorrido a unos quinientos metros de las casas de los pescadores. A las características de la frecuencia del servicio de transporte ${ }^{7}$ en la zona se suma que no exista una red de agua potable, y que hasta hace aproximadamente unos cuatro años estas casas no tenían tendido de luz eléctrica. Esto último permitió el uso de freezers para guardar las capturas. Los servicios sanitarios y educativos se encuentran en Rocha y Maldonado, pero en general las personas se trasladan hasta Rocha.

\section{Las especies objetivo de la pesquería.}

7 La Empresa de Transporte Compañía Oriental de Transporte (COT) hace cuatro viajes diarios (dos en la mañana y dos en la tarde) desde Montevideo hasta Laguna Garzón. Por otro lado la Empresa COPSA realiza tres viajes diarios (uno en la mañana y dos en la tarde) desde Montevideo hasta la Laguna. 
La principal fuente de ingreso de los pescadores proviene de la pesca de especies residentes de estos ambientes estuarinos de baja salinidad. Como el pejerrey (Odonthestes argentiniensis), lenguado (Paralicthys orbignianus) y lisas (Mugil spp.), y tiempo atrás de la extracción del berberecho de laguna (Erodona mactroides) (Beovide, Martínez y Norbis, 2014). La lacha (Brevoortia aurea) es muy abundante y se comercializa para uso como carnada para la pesca de brótola (Urophycis brasiliensis) en el mar. En condiciones de barra abierta o cerrada. pero en la zona externa de la barra, se pesca corvina rubia, (Micropogonias furnieri) y corvina negra (Pogomias cromis). Las zafras de camarón (Farfantepenaeus paulensis) solo se dan en condiciones de barra abierta, las cuales son poco frecuentes. En bolsones interiores y subestuarios de arroyos que descargan en la laguna, y en condiciones de no apertura de la barra (muy baja salinidada) la actividad pesquera está dirigida al bagre negro (Ramdhia quelen) y a la especie introducida carpa (Cyprinus carpio) y (Santana y Fabiano, 1999).

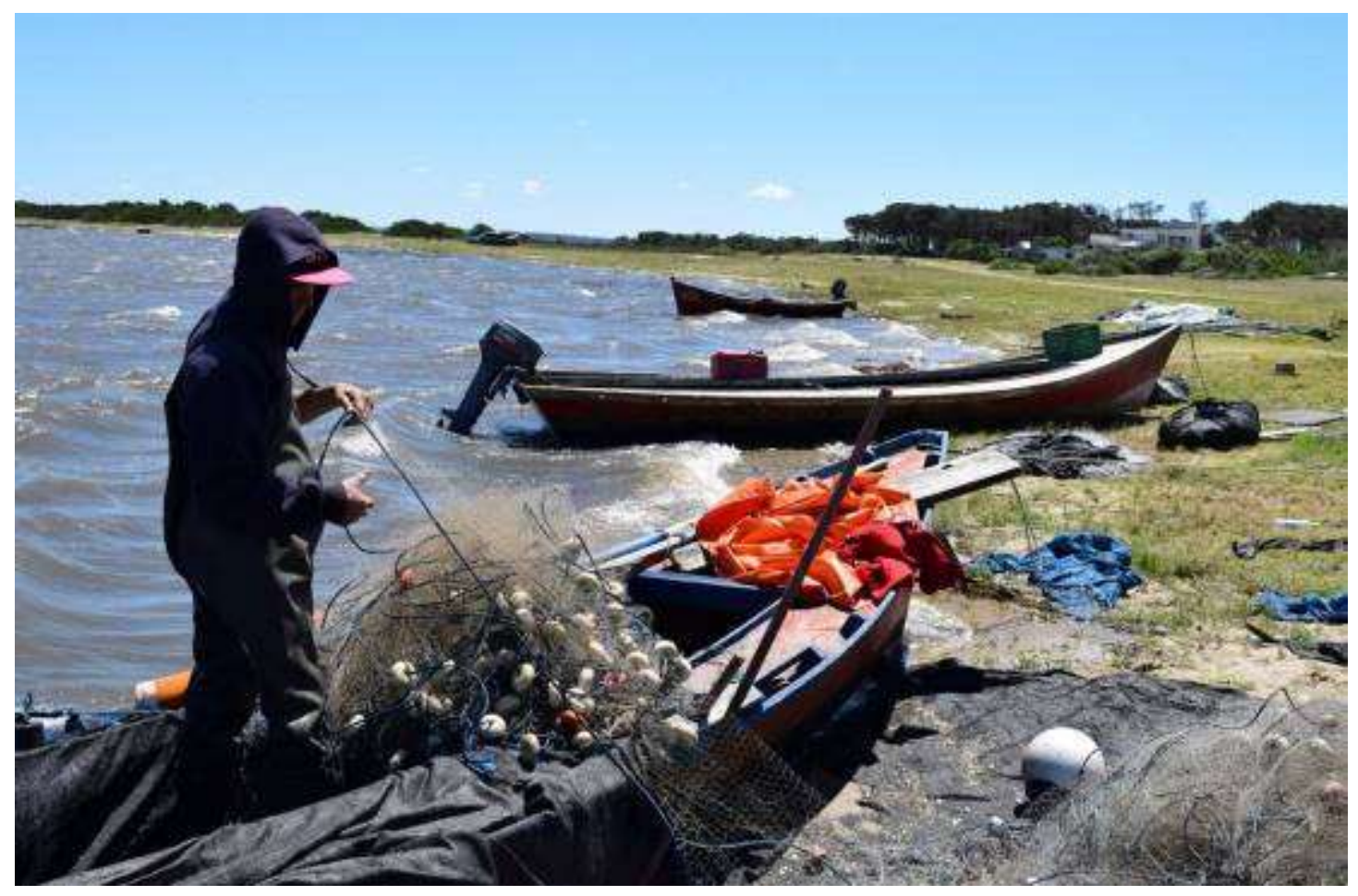

Figura 8- Preparación de redes de pesca. Laguna Garzón, 9 de mayo de 2018.

Las modalidades de pesca y las artes de pesca. 
El conocimiento de las especies revela un complejo corpus sobre sus características y movimientos. Estas están en relación con las condiciones que presenta la laguna, entre otros elementos que inciden en la presencia o ausencia de una especie buscada. Se observa una marcada estacionalidad, un calendario ecológico y un calendario social.

La territorialidad nativa y las formas de georreferenciación en la laguna se vinculan con la movilidad y características de las especies capturadas, así como a la conexión del agua dulce o salobre con el espacio oceánico. El entorno está marcado por un gran dinamismo en el que interactúan humanos y no-humanos.

La pesca artesanal no ha cambiado tanto con el paso del tiempo y la actividad sigue demandando de esfuerzo físico tanto en las pequeñas barcas como en tierra firme, y además conlleva un importante trabajo manual al igual que gran parte de la flota artesanal del país (de Álava y Rodríguez, 2007; Vitancurt y Fagetti,1995).

La pesca en la laguna se presenta como una actividad de un esfuerzo físico significativo, aunque representa un bajo nivel de riesgo. Se presta así para que pescadores de edad más avanzada y sin ánimos de "aventuras marítimas" tengan jornadas de trabajo amplias, aunque intermitentes y de capturas bastante regulares bajo condiciones climáticas generosas.

En dicho sentido, la pesca es realizada mediante el uso de trasmallos o redes que suelen ser colocadas en tempranas horas de la mañana, antes incluso de la salida total del sol, son capturadas especies como la lisa, el lenguado y el pejerrey principalmente, aunque también se registran capturas de lacha, sirí y camarón.

Las redes se mantienen en el agua durante varias horas. El viaje en la chalana con motor fuera de borda puede conllevar una hora o a veces más, por lo que, si bien el período de actividad efectiva de los pescadores con sus artes de pesca es acotado, la preparación, así como la disposición del material, complementan una jornada laboral de una extensión horaria importante que se extiende a lo largo de todo el día (Figura 9). En cuanto a las embarcaciones, oscilan entre los cinco y seis metros de eslora, algunas son realizadas en madera y fibra por los mismos pescadores que a lo largo de los años han aprendido las técnicas de carpintería, o bien las compraron hace muchos años y suelen remendar por sus propios medios. Muchas tienen más de veinte años y han ido pasando de generación a generación.

Ahora bien, seguido de la captura y la recogida de las redes se realiza la limpieza del pescado, en una mesa colocada sobre la misma orilla donde las aves se acercan para 
convertirse en los gestores de los desperdicios extraídos del interior de los peces, el pescado es limpiado y fileteado a través de diferentes técnicas.

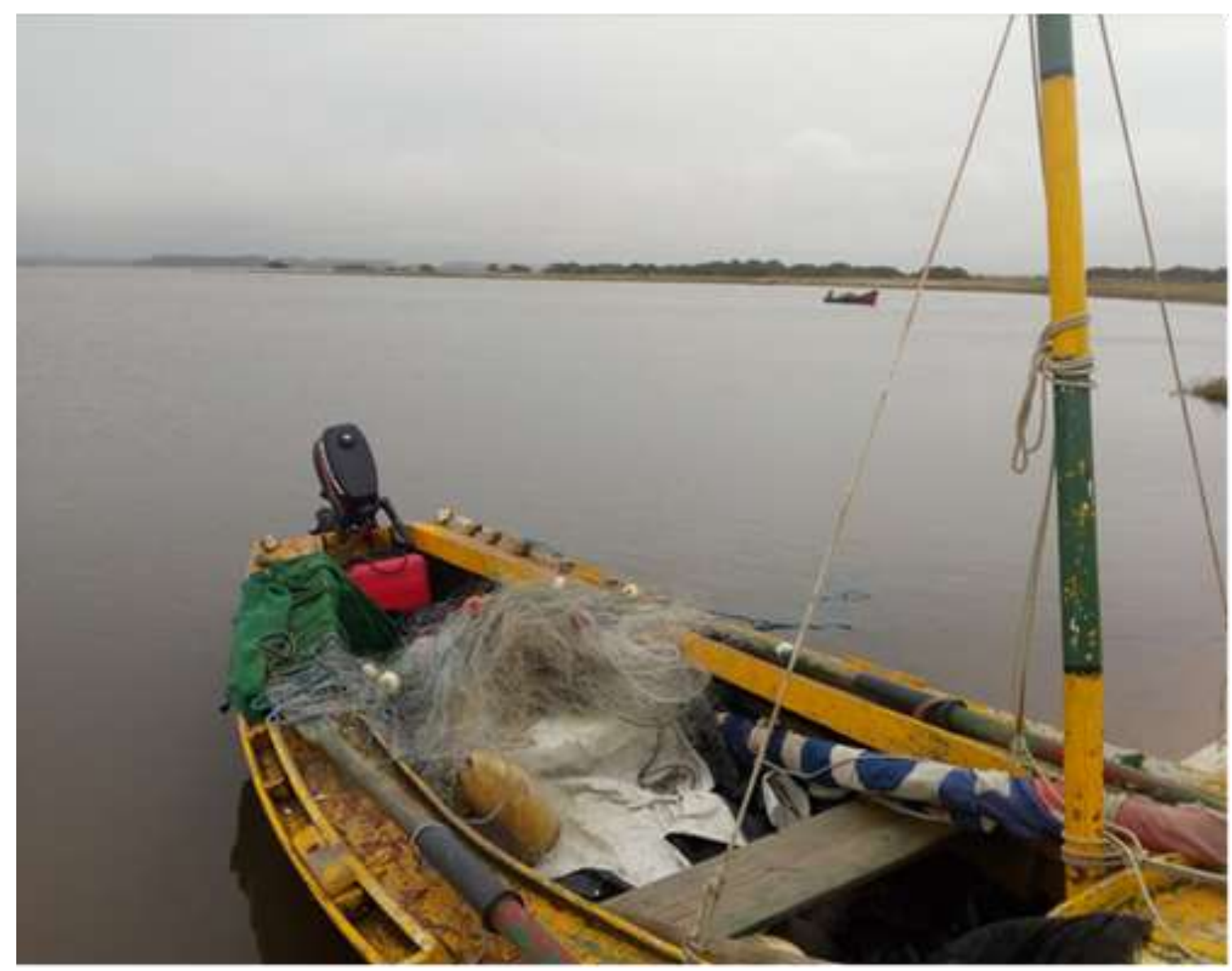

Figura 9- Embarcación en Laguna Garzón, 27 de octubre de 2017.

Luego de fileteado el pescado aguarda dentro de los cajones en el freezer a que sea coordinada la visita del comprador (Figura 10). Si bien todos los pescadores de la Laguna tienen diferentes destinos para sus capturas: unos venden a una pescadería en Rocha, otros hacia Maldonado, y hay también quienes venden directamente al público, muchas veces a extranjeros interesados en especies poco convencionales como el cangrejo sirí o el camarón (ausente en las últimas temporadas). ${ }^{8}$

8 Han surgido en el trabajo de campo diferentes especies de las cuales aún no conocemos la verdadera presencia actual y sus capturas históricas, entre ellas podrían enumerarse: lenguado, lisa, brótola, bagre, corvina negra, corvina blanca, camarón, pejerrey, sirí, la almeja que se cuenta anecdóticamente que hubo alguna vez y la lacha que no se vende para consumo humano sino como carnada. 


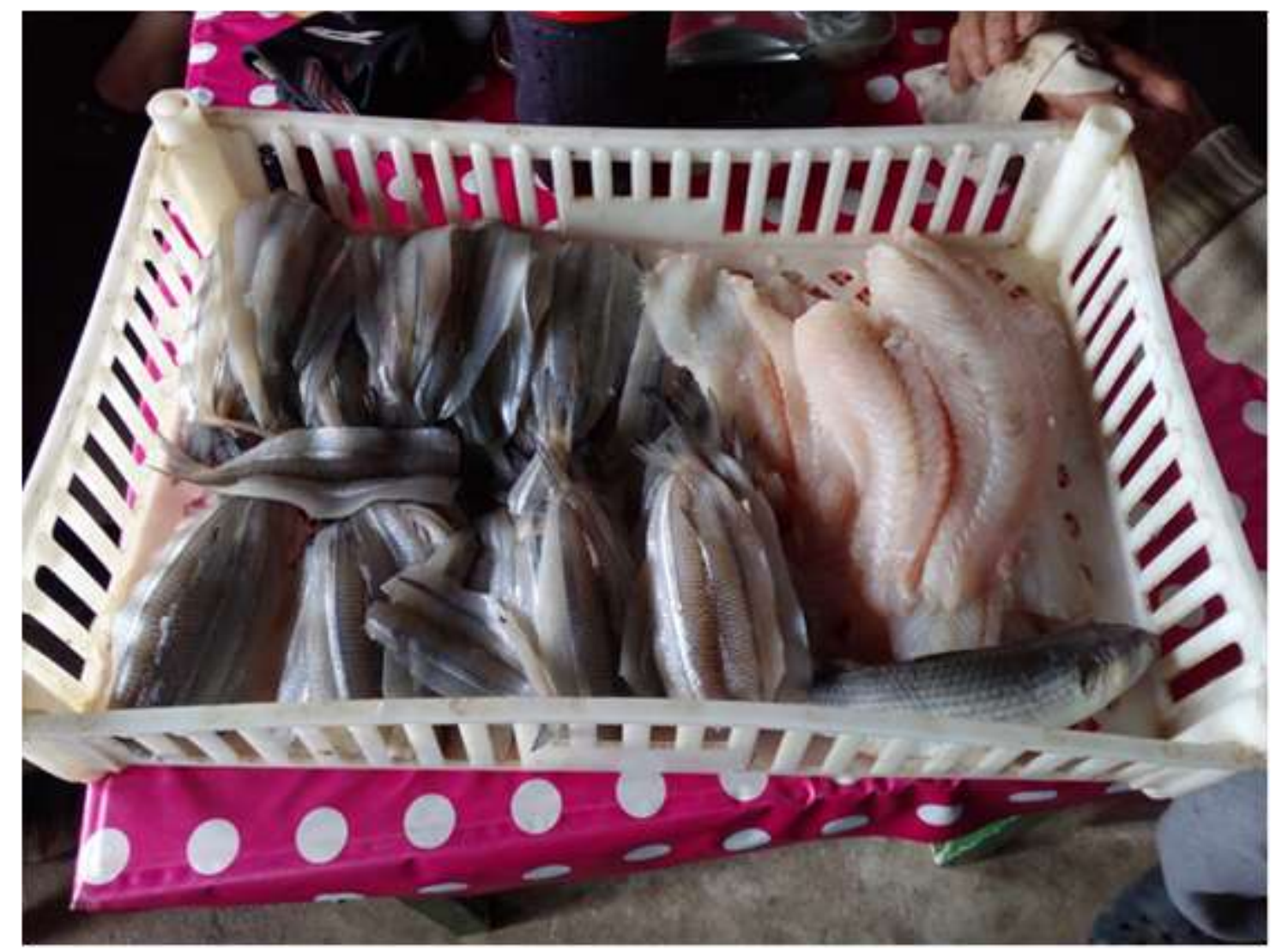

Figura 10- Fileteado de la pesca. Laguna Garzón, 27 de octubre de 2017.

\section{Ser pescador artesanal.}

Los residentes permanentes de la laguna se dedican a la pesca artesanal, son seis personas, mayores de cincuenta años que tienen al menos treinta años realizando dicha actividad en la zona. Cabe destacar que en la actualidad la pesca sigue siendo su principal actividad económica y ocasionalmente realizan otros trabajos como paseos a los turistas que visitan la laguna. Existe una única casa de pescadores que se ubica al otro lado del puente (Maldonado), que a su vez funciona como un puesto de venta directa al público.

Un dato interesante que surgió en las entrevistas es la movilidad de los pescadores, en tal sentido, varios informantes relataron que anteriormente se trasladaban a las lagunas de: Rocha, José Ignacio o Valizas para las zafras, en donde permanecían por varios días en casas de amigos o acampando, pero que al envejecer han ido quedándose en Laguna Garzón. También observamos el caso de pescadores que tienen su residencia permanente en la laguna de Rocha y visitan ocasionalmente laguna Garzón. Las lagunas aparecen para los pescadores 
interlocutores de este trabajo, como un espacio con continuidad en el que las distancias se resignifican desde esta perspectiva, en comparación con lo que a simple vista aparece en el territorio.

Una de las problemáticas detectadas por los pescadores es que las nuevas generaciones se vinculan a otro tipo de trabajos y no escogen la pesca Uno de los elementos que ha acentuado esta elección es la escasez de peces en la laguna desde hace varios años.

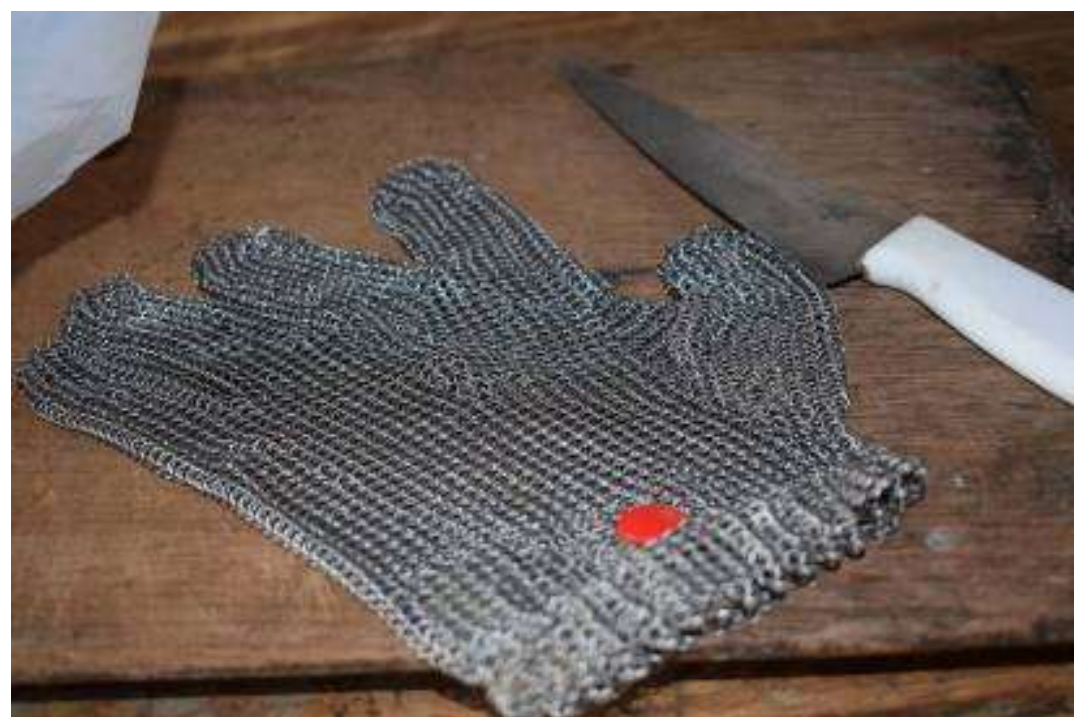

Figura 11- Guante de acero y cuchillo utilizado para filetear el pescado. Laguna Garzón, 9 de mayo de 2018.

En el trabajo de campo en la laguna observamos muy pocos jóvenes involucrados con la pesca, estos se vuelcan al sector de servicios turísticos, actividad ésta muy relevante en la zona.

En los meses de verano (diciembre, enero y febrero) es cuando transitan y permanecen mayor cantidad de personas en la laguna y comienzan a funcionar los establecimientos turísticos (hotel, restaurante y escuela de kitesurf), que cabe destacar, el resto del año permanecen en su mayoría cerrados. 


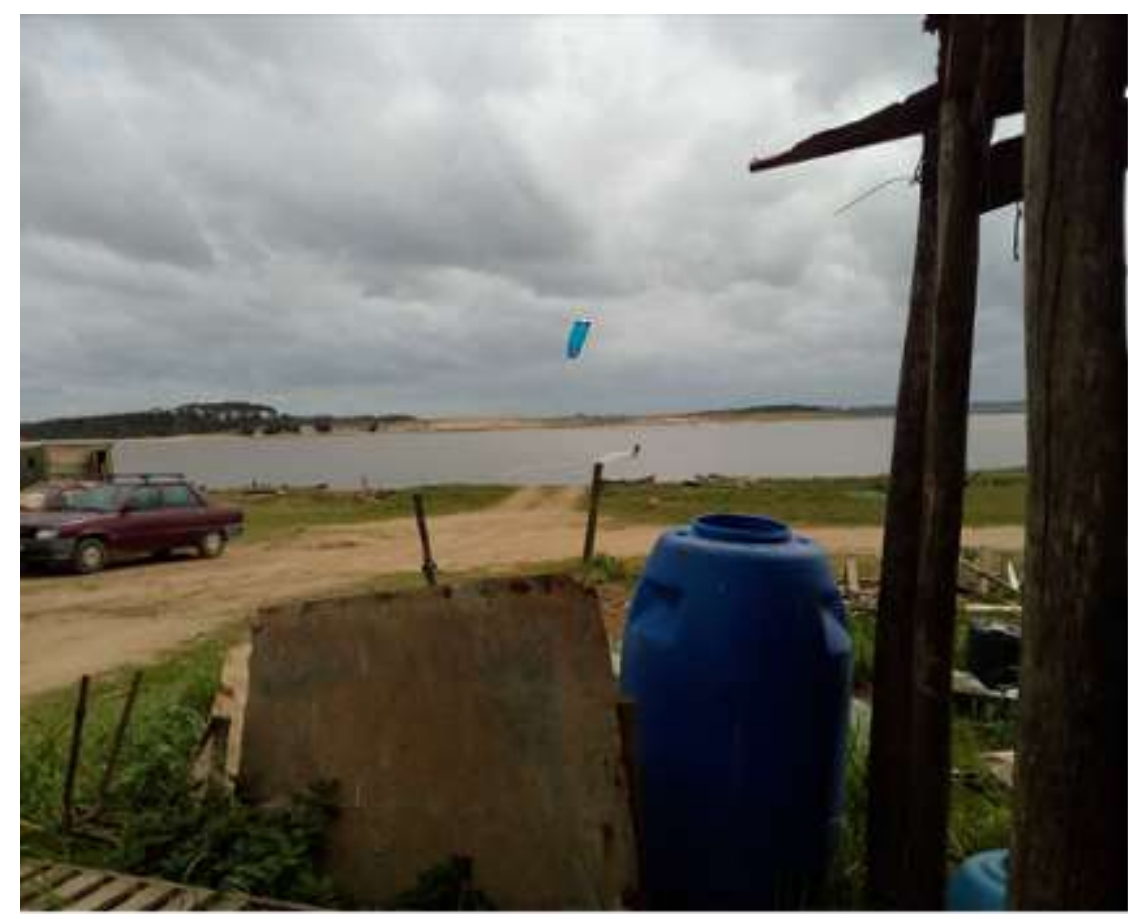

Figura 12 - Práctica de kitesurf desde casa de pescador. Laguna Garzón, 27 de octubre de 2017.

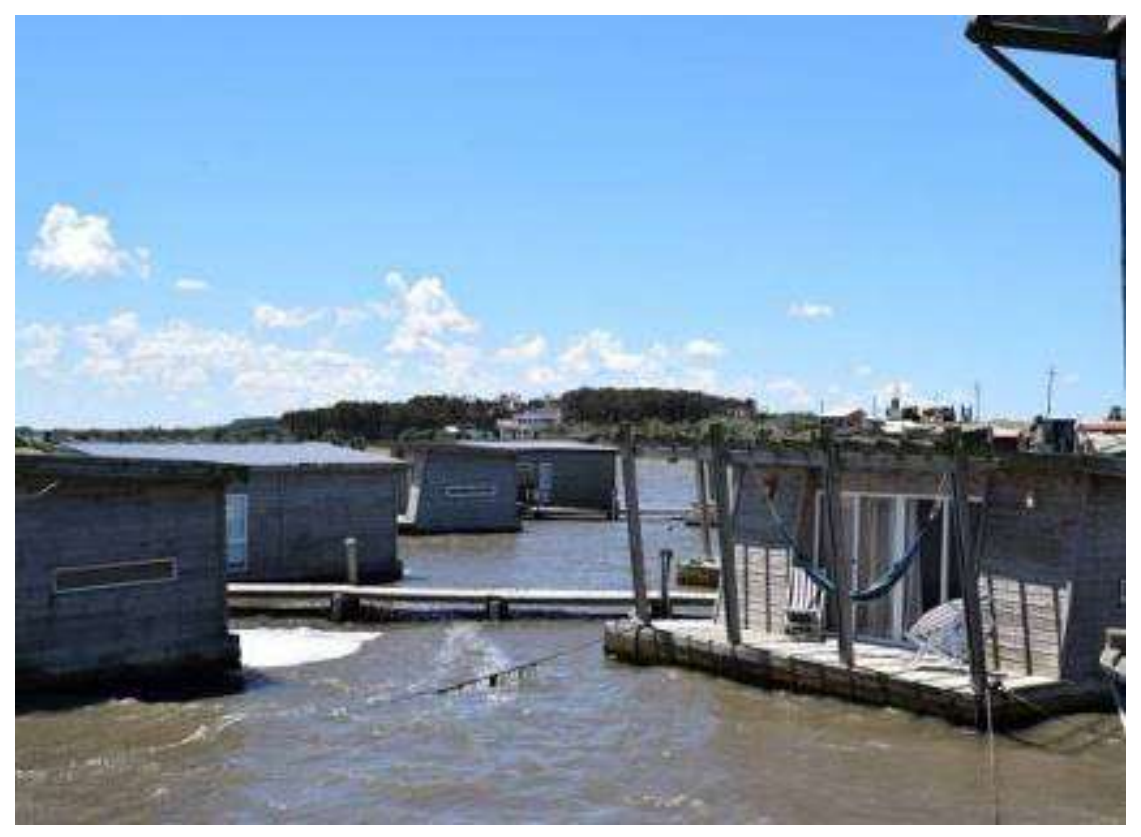

Figura 13- Hotel Laguna Garzón Lodge Hotel Flotante. Laguna Garzón, 9 de mayo de 2018.

Existen varios factores que hacen de Laguna Garzón un área de grandes interacciones sociales entre los diferentes actores vinculados a su ecosistema. Encontramos a los residentes de todo el año, los estivales y los que presentan servicios turísticos, las intendencias de Maldonado y Rocha que encuentran sus respectivos límites en la laguna. Las intendencias operan en diferentes ocasiones y persiguen sus propios intereses para con la zona, a veces 
contravenientes entre sí. Además, se encuentran las diferentes instituciones gubernamentales vinculadas a la regulación y protección de la biodiversidad como el caso de la DINAMA y la DINAGUA están vinculadas del mismo modo. A su vez la zona de Laguna Garzón es parte del Sistema Nacional de Áreas Protegidas (SNAP) de la DINAMA, de modo que existe una oficina en la cual suelen haber dos funcionarios guardaparques encargados de fiscalizar y controlar la protección de la biodiversidad de la zona que comprende tres grandes fases: el bosque psamófilo propio de la zona oceánica costera de Uruguay, el cuerpo de agua de laguna y la faja de dunas costeras. Las diferentes acciones que realizan dichas instituciones se ven muchas veces conflictuados con los intereses o la misma vida cotidiana de los pobladores de acuerdo a la percepción de nuestros interlocutores.

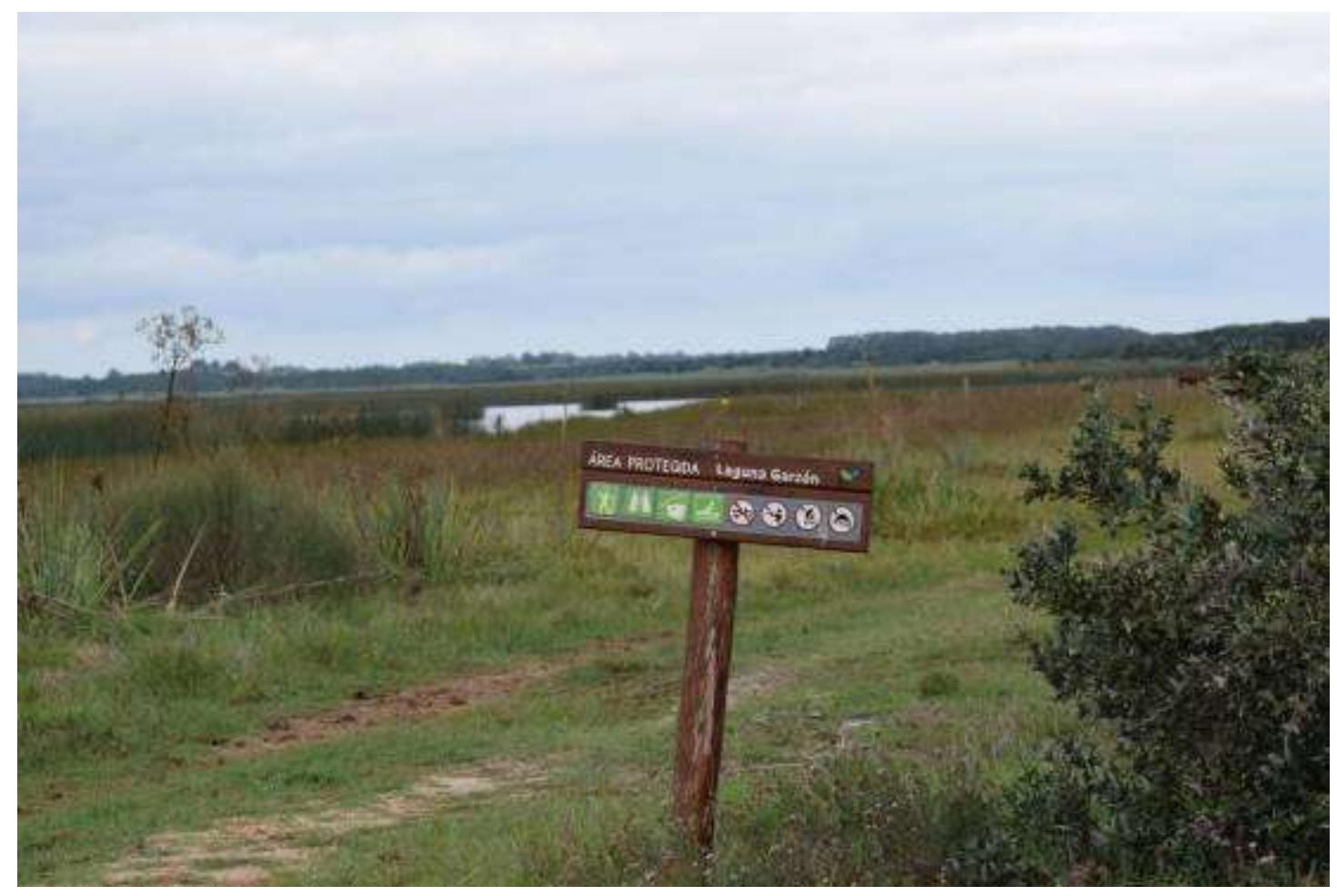

Figura 14- Vista del entorno de Laguna Garzón con cartel de Área Protegida. Laguna Garzón, 27 de octubre de 2017.

Para los funcionarios que entrevistamos en la oficina del Área Protegida el ingreso de Laguna Garzón al SNAP surgió en el año 2014 como contrapartida por el advenimiento de un mayor daño ecológico a causa de la colocación del ya mencionado puente circular. ${ }^{9}$ Esto hace

9 El ingreso como Área Protegida se da mediante el decreto 341-2014 que avala dicha acción en la protección de la biodiversidad ya contemplada en anteriores legislaciones que valorizaban dicha 
del Área una zona nueva a considerar por las legislaciones, las regulaciones y pone a los funcionarios de dicha área en una tarea a comenzar desde cero y con una amplia gama de impedimentos para realizar su labor. La prohibición a los vehículos de ingresar a la faja costera así como el impedimento del daño a la zona boscosa por toda clase de actividades, que van desde la caza furtiva a la construcción irregular o la tala de árboles, suelen ser las tareas de prevención cotidianas.

En este momento el Área Protegida se encuentra en el proceso de elaboración de su plan de manejo, una de las temáticas que se planteó como prioritaria por parte de diversos actores sociales es la apertura artificial con máquina de la barra.

\section{Apertura de la barra}

Las dinámicas del agua a través de la barra de la laguna, por estar conectada con el mar a través de ella, hace que influya ya que del mar provienen los peces, algunos de los cuales desovan en la laguna. Existen algunas similitudes en las formas de describir estas dinámicas entre los pescadores de Laguna Garzón y los del caso estudiado por Moura y Diegues (2009) en el Saco do Arraial en la Laguna dos Patos al sur de Brasil. Por ejemplo en terminologías que identifican las acciones que el agua realiza como cuando "as aguas se péixam", es decir "cuando el agua salada pecha al agua dulce" como nos decía el pescador de Laguna Garzón. Del mismo modo, ambos grupos de pescadores comprenden a la barra como la conexión de la laguna con el océano (Moura y Diegues, 2009:364) y que por tanto, ésta es determinante en todo lo que ocurre en relación a la pesca. En la misma dirección ocurre en el estudio de da Silva Mello y Vogel (2017:71) en Maricá- RJ, donde "el matrimonio entre las aguas del mar con las aguas de la laguna adquiere una relevancia especial”. "Aprisionando un brazo de mar, se introduce esa parte de océano en la temporalidad distinta de las aguas interiores, privándola, de su originaria autonomía como hábitat. La laguna que resulta de ese proceso dependerá no

zona como patrimonio ecológico de relevancia internacional: "por su diversidad de ambientes representativos de la costa atlántica uruguaya, previo al proceso de intervención antrópica, presentando un fuerte valor natural y patrimonial, siendo un símbolo de ecosistemas autóctonos, por cuanto cuenta con la presencia de especies de prioridad para la conservación, tanto a nivel nacional como internacional, con gran relevancia para la conectividad ecosistémica y poblacional a nivel costero, así como por su grado de naturalidad, vulnerable a factores externos". https://www.impo.com.uy/bases/decretos/341-2014. 
solamente de la relación con las aguas de tierra, para la reproducción de su variada y múltiple riqueza biológica sino que además de los caminos de la vida que vienen del mar" (da Silva Mello y Vogel, 2017:84). En este estudio los autores mencionados ponen de relieve el significado que los pobladores, daban a la apertura artificial de la barra. Acción que era considerada como un rito colectivo, en el que además de trabajo se compartían canciones y alimentos. Este proceso es descripto por los nativos como la fecundación del mar a la laguna (da Silva Mello y Vogel, 2017). En el caso de estudio presentado aquí, surge la preocupación por la apertura artificial de la barra mediante máquinas a destiempo. Desde la observación de los pescadores, esto ha traído como consecuencia la ausencia de peces. De acuerdo a lo que observamos en el trabajo de campo, en la actualidad no existe consenso para su apertura, es decir cuándo debe hacerse este procedimiento y bajo qué parámetros. Por ello, la Comisión Asesora Específica del Área se encuentra trabajando en el establecimiento de un Protocolo de Apertura.

Cabe destacar que en otras lagunas como la de Rocha existe un sistema de manejo que entre otras cosas contempla un protocolo que fija las pautas para la apertura de la barra. Tal como señalan Lagos, Dabezies, Delgado y Cetrulo, (2017), allí se elaboró un protocolo contemplando e incluyendo el conocimiento generado en las prácticas de la localidad por pescadores artesanales que antiguamente realizaban la apertura manual de la barra, cuando la misma estaba a punto de caer, por lo que insumía un día o dos de trabajo y era un momento de trabajo colectivo y de encuentro. Siendo este aspecto el principal desafío que se plantea para el desarrollo del protocolo de apertura de la barra de Laguna Garzón.

\section{Consideraciones finales}

En los casos estudiados se presenta como desafío y oportunidad el diálogo de saberes y las conjugaciones de conocimientos: científicos y el generado en las prácticas de la localidad por los pescadores. Como desafío en tanto que implica el conocer y reconocer dicho conocimiento como insumo para los planes de gestión de los recursos (por ejemplo en el cálculo de la biomasa de almeja) y de los ecosistemas (por ejemplo en la modalidad y momento de apertura de la barra de la laguna). Finalmente se plantea como oportunidad pues el contar con la permanencia y transformación de estos conocimientos trasmitidos durante décadas en ambas áreas, es una fuente de información muy valiosa para la gestión y la 
comprensión de los ecosistemas y sus transformaciones. Así como para la producción de conocimiento científico: antropológico, biológico, entre otros.

En este sentido, este proyecto ha sido una oportunidad para abordar con matices comparativos, dos casos de estudio en donde se están implementando dos formas de manejo y gestión de los recursos costeros y lacustres, en particular. Asimismo del análisis surgen diversos actores sociales vinculados directamente con el sector productivo de la pesca artesanal, como con el desarrollo del turismo (presente en ambos casos) e instituciones que están involucradas de modos diversos en los diferentes casos. Aparecen conflictos y desafíos vinculados a la agencia humana sobre los entornos y los modelos de desarrollo propuestos pero también a agencias no-humanas, donde ambas dan cuenta de cambios medioambientales, de ontologías y ecologías diversas.

El proyecto, en el que se enmarca este artículo ha buscado articular diversas formas de entender y conocer el entorno lacustre y costero. Coincidiendo en este sentido con Milton, (1997), quien señala que "en el ámbito de la antropología, así como en algunas otras disciplinas, el interés por los modos en que la gente se relaciona con el medio ambiente no es nuevo: pero las conclusiones a que ha llevado esta investigación nunca han sido tan potencialmente significativas para el mundo no académico como lo son ahora en el contexto del discurso medioambiental contemporáneo" (Milton, 1997:2).

Por otro lado, la narrativa sobre el vínculo ambiente-sociedad o cultura-naturaleza (Christie, 2004, Kopnina, 2012), desarrollada actualmente con la visión holística de los Sistemas Sociales-Ecológicos (Ostrom, 2009) da el marco ideal para el trabajo interdisciplinar. En este proceso existen obstáculos reales y al mismo tiempo oportunidades que permiten el trabajo conjunto entre disciplinas sociales y las vinculadas a las ciencias naturales (Escobar, 1996; Campbell, 2005; West, Igoe y Brockington, 2006; Taks, 2009; Breslow, 2015). En este sentido, la premisa de "asegurar la sustentabilidad de los recursos naturales para las siguientes generaciones" ofrece un marco donde todas las disciplinas podemos transitar y coincidir. 


\section{Bibliografía}

Araujo, O. (1903). Diccionario Geográfico del Uruguay. Montevideo: Imprenta Artística de Dornaleche y Reyes.

Basurto, J. (2005). How Locally Designed Access and Use Controls Can Prevent the Tragedy of the Commons in a Mexican Small-Scale Fishing Community. Society \& Natural Resources, 18 (7), 643-659.

Beovide, L., Martínez, S. y Norbis, W. (2014). Etnobiología de Erodona mactroides (Mollusca, Bivalvia). Análisis especial y tafonómico de concheros actuales. Revista Etnobiología 12 (2), 519.

Berkes, F. (2008). Las pesquerías artesanales de pequeña escala: alternativas al manejo convencional de recursos. En: Pinedo, D., Soria, C.(Ed.), El manejo de pesquerías tropicales de Sudamérica. Centro Internacional de Investigaciones para el Desarrollo.

Breslow, S. J. (2015). Accounting for neoliberalism: "Social drivers" in environmental management. Marine Policy, 61, 420-429.

Campbell, L. M. (2005) Overcoming Obstacles to Interdisciplinary Research. Conservation Biology, 19, 574-577.

Christie, P. (2004). Marine Protected Areas as Biological Successes and Social Failures in Southeast Asia. American Fisheries Society Symposium, 42,155-164.

D’Ambrosio, L. (2010). Esto es zafral todo, el mejillón, el mingo y la brótola. En:

D’ Ambrosio, L., Lembo, V., Amato, B. y Thompson, D. El mundo sumergido. Una investigación antropológica de la pesquería del mejillón en Piriápolis y Punta del Este, Montevideo, Uruguay: Publicaciones de FHUCE. 
Da Silva Mello, M. y Vogel, A. (2017). Gente das Areias. História, meio ambiente e sociedade no litoral brasileiro. Editora da Universidade Federal Fluminense, Série Universidade, 4. Recuperado de: https://issuu.com/eduff editora/docs/pdfjoiner

De Álava, D. y Rodríguez, L. (2007). Zona Costera de la Laguna Garzón: Recomendaciones para su conservación y manejo. Recuperado de: http://www.guayubira.org.uy/2007/11/zonacostera-de-la-laguna-garzon-recomendaciones-para-su-conservacion-y-manejo/

De La Rosa, A. (2016). Caracterización socioecológica de la pesquería artesanal de almeja amarilla y uso del conocimiento tradicional para su manejo. Recuperado de: https://www.colibri.udelar.edu.uy/jspui/bitstream/123456789/8413/1/uy24-18165.pdf

Defeo, 0. (1989). Development and management of artisanal fishery for yellow clam Mesodesma mactroides in Uruguay. Fishbyte, 7 (3), 21-25.

Defeo, O. (1996). Experimental management of an exploited sandy beach bivalve population. Revista Chilena de Historia Natural, 69, 605-614.

Defeo, O., Castrejón, M., Ortega, L., Kuhn, A. M., Gutiérrez, N. L. y Castilla J. C. (2013). Impacts of climate variability on Latin American small-scale fisheries. Ecology \& Society, 18 (4), 30.

Defeo, 0. (2015). Enfoque ecosistémico pesquero: Conceptos fundamentales y su aplicación en pesquerías de pequeña escala de América Latina. FAO Documento Técnico de Pesca y Acuicultura, FAO, Roma, 84.

Defeo, O., Gianelli, I., Martínez, G., Ortega, L., Celentano, E., Lercari, D. y De La Rosa, A. (2018). Natural, social and governance responses of a small-scale fishery to mass mortalities: the yellow clam Mesodesma mactroides in Uruguay. En: Patrice Guillotreau, Alida Bundy and R. Ian Perry (Ed.), Societal and governing responses to global change in marine systems. Routledge Studies in Environment, Culture, and Society Series. 
Dornel, J. (s/f). La Barra del Chuy, historia de un balneario. Recuperado de: http://www.revistahistoricarochense.com.uy/rhr-no-\%205/la-barra-\%20del-chuy\%20historia-de-\%20un-balneario/

Etchebehere, C. y Geymonat, J., (2018). La pesca artesanal y su inserción en el desarrollo del complejo pesquero. En: Etchebere, C., Galli, O., Geymonat, J., Mendy, M., Morales, S., Norbis, W. (Ed.). Análisis del complejo pesquero uruguayo: una experiencia de investigación y extensión con los trabajadores del mar. CSEAM, Universidad de la República, Uruguay.

Escobar, A. (1996). Construction Nature. Elements for a post-structuralist political ecology. Futures, 28 (4), 325-343.

Florido, D. (2002) El saber hacer y los sentidos de los pescadores andaluces. Demófilo. Revista de Cultura Tradicional. Tercera época, (1), 19-38.

Gianelli, I., Martínez, G. y Defeo, O. (2015). An ecosystem approach to small-scale co-managed fisheries: the yellow clam fishery in Uruguay. Marine Policy, 62, 196-202.

García-Allut, A., (2003). La pesca artesanal, el cambio y la patrimonialización del conocimiento. Debate e Investigación, 44, 75-83.

Ingold, T. y Kurttila, T. (2000). Perceiving the Environment in Finnish Lapland. Body and Society, 6 (3-4), 183-196.

Kopnina, H. (2012). Re-examining culture/conservation conflict: the view of anthropology of conservation through the lens of environmental ethics. Journal of Integrative Environmental Sciences. Science, 9 (1), 9-25.

Lagos, X., Dabezies, J., Delgado, E. y Cetrulo, R. (2017). Vínculos para la gestión: dinámicas socioinstitucionales y perspectivas para el manejo integrado de la pesca artesanal en Laguna de Rocha (Uruguay). REDES Revista Hispana para el Análisis de Redes Sociales, 28 (1), 47-60. 
Lercari, D. y Defeo, O. (2006). Efectos del Canal Andreoni en playas de Rocha: deterioro ambiental y su efecto en la biodiversidad. En: Menafra, R., L., Rodríguez-Gallego, L., Scarabino, F., Conde, D., (Ed.). Bases para la conservación y el manejo de la costa uruguaya.

Lobo, M. y Riudavets, P. (1868). Manual de la navegación del Río de La Plata y de sus principales afluentes, con instrucciones para la recalada y derrotas de ida y vuelta á Europa, según los documentos más fidedignos, nacionales y extranjeros, por los señores Lobo y Riudavets. Madrid: Establecimiento tipográfico de T. Fortanet.

Lozoya, J.P. y Defeo, O. (2006). Effects of a freshwater canal discharge on an ovoviviparous isopod inhabiting an exposed sandy beach. Marine and Freshwater Research 57, 421-428.

Migliaro, A. y Santos, C. (2010). La pesca no es sólo eso: producción, reproducción social y ambiente. Sobre pesca artesanal y variabilidad climática en el Uruguay. Revista Sociedad Latinoamericana, 2 (3) San Juan Aragón, México.

Milton, K. (1997). Ecologías: antropología, cultura y entorno. Recuperado de:

htttp://www.universidadur.edu.uy/retema/archivos/Antropología_Cultura_Entorno_Milton_ K.pdf.

Morais Chiaravalloti, R. (2019). The Displacement of Insufficiently 'Traditional' Communities: Local Fisheries in the Pantanal. Conservation and Society, 17 (2), 173-183.

Moura, G. y Diegues, A. (2009). Os conhecimentos tradicional e científico do saco do Arraial, Estuário da Lagoa dos Patos (RS), B. Inst. Pesca, São Paulo, 35 (3), 359-372.

Ortega, L., Castilla, J.C, Espino, M., Yamashiro, C. y Defeo, O. (2012). Effects of fishing, market price, and climate on two South American clam species. Marine Ecology Progress Series 469, 71-85.

Ostrom, E. (2009). A General Framework for Analyzing Sustainability of Social-Ecological Systems. Science, 325 (5939), 419-422. 
Palsson, G. (1989). Report of the international symposium on marine environment and future of the fisher-workers. Recuperado de: http://icsf.net/icsf2006 /uploads/publications/ proceeding/pdf/english /issue_5/ALL .pdf

Puig, P., Grunwaldt, P. y González, S. (2010). Pesquería artesanal de corvina en Uruguay. Frente Marítimo 21, 23-35.

Reyes, J. M. (1859). Descripción geográfica del territorio de la República Oriental del Uruguay. Montevideo: Establecimiento Tipográfico y Litográfico de Luciano Mége.

Romero, J., G., Lercari, D., Ortega, L. y Defeo, O. (2019). Long-term ecological footprints of a man-made freshwater discharge onto a sandy beach ecosystem. Ecological Indicators, 96, 412420.

Saavedra-Díaz, L. M., Rosenberg, A. A. y Martín-López, B. (2015). Social perceptions of Colombian small-scale marine fisheries conflicts: Insights for management. Marine Policy 56, 61-70

Santana, O. y Fabiano, G. (1999) Medidas y mecanismos de administración de los recursos pesqueros de las lagunas costeras del litoral atlántico del Uruguay (Lagunas de José Ignacio, Garzón, Rocha y Castillos). Proyecto de Investigaciones Pesqueras INAPEPNUD-URU/92/003.

Santos, C. (2011). ¿Qué protegen las áreas protegidas? Conservación, producción, Estado y Sociedad en la implementación del Sistema Nacional de Áreas Protegidas. Montevideo, Uruguay: Editorial Trilce.

Santos, C. (2017). Fronteras Líquidas: El impulso al agronegocio a partir de la nueva política de riego en Uruguay. En: Experiencias de avance del agronegocio en los países del Mercosur: actores, instituciones, políticas públicas, organización y resistencias. XII Reunión de Antropología del Mercosur (RAM) GT No 63.

Sauco, S., Eguren, G., Heinzen, H. y Defeo, O., (2010) Effects of herbicides and freshwater discharge on water chemistry, toxicity and benthos in a Uruguayan sandy beach. Marine Environmental Research, 70, 300-307.

Sosa, F. (2006). Centro de Ecoturismo Sustentable Laguna Garzón Rocha. Recuperado de: http://www.mvotma.gub.uy/reglamento/item/10002991-centro-de-ecoturismosustentable.html

Sosa, G. (2007). La Coronilla: balneario caído en desgracia. Diario El País, Suplemento Que Pasa. Http://www.portaldeluruguay.com/index.php/component/k2/item/970-la-coronillabalneario-caido-en-desgracia. 
Taks, J., (2009). Los desafíos de la antropología para la comprensión de los conflictos socioambientales en Sudamérica, En: Conflictos actuales del desarrollo rural y ambiental: una interpelación a la Antropología. Reunión de Antropología del Mercosur, Buenos Aires.

Recuperado de: http://es.scribd.com/doc/61043538/ponencia-RAM-JTAKS.

Vitancurt, J. y Fagetti, C. (1995). Comunidades de pescadores del departamento de rocha. informe diagnóstico y recomendaciones para un proyecto de desarrollo. Recuperado de: https://www.probides.org.uy/PUBLICA/DT/DT01.PDF

West, P., Igoe, J. y Brockington, D. (2006). Parks and Peoples: The Social Impact of Protected Areas. Annual Review of Anthropology, 35, 251-277.

\section{Fotografías}

Equipo de trabajo Proyecto CSIC I+D CURE-UDELAR (Laguna Garzón - La Coronilla. 2017 2018). 